Portland State University

PDXScholar

$11-1-1990$

\title{
Communication Stressors and Coping Strategies Among Chinese Students in the United States
}

Qiu Lu Liang

Portland State University

Follow this and additional works at: https://pdxscholar.library.pdx.edu/open_access_etds

Part of the International and Intercultural Communication Commons

Let us know how access to this document benefits you.

\section{Recommended Citation}

Liang, Qiu Lu, "Communication Stressors and Coping Strategies Among Chinese Students in the United States" (1990). Dissertations and Theses. Paper 4184.

https://doi.org/10.15760/etd.6068

This Thesis is brought to you for free and open access. It has been accepted for inclusion in Dissertations and Theses by an authorized administrator of PDXScholar. Please contact us if we can make this document more accessible: pdxscholar@pdx.edu. 
AN ABSTRACT OF THE THESIS OF Qiu Lu Liang for the Master of Arts in Speech Communication presented November 1, 1990.

Title: Communication Stressors and Coping Strategies Among Chinese Students in the United States.

APPROVED BY THE MEMBERS OF THE THESIS COMMITTEE:

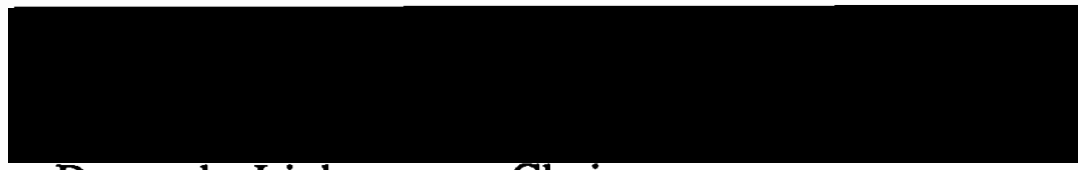

Devorah Lieberman, Chair

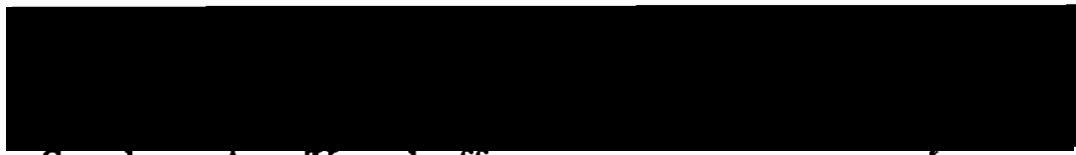

Stephen A. Kosokoff
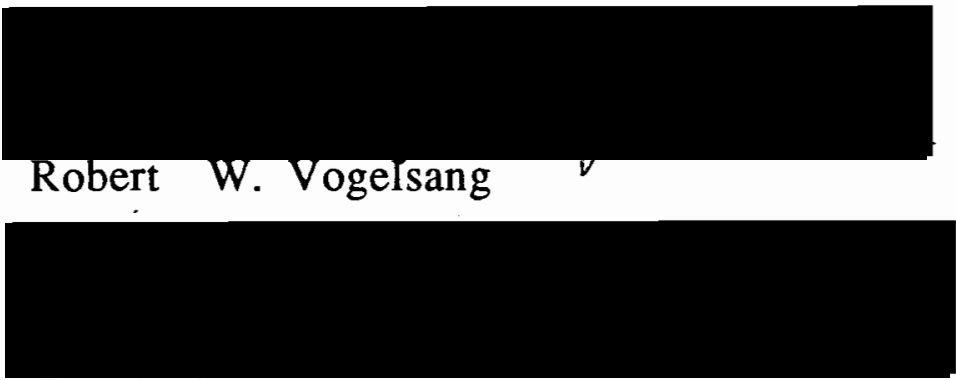

Connie Dawson

Following China's open door policy in the late 70's and early 80 's, there has been a significant increase in the number of Chinese students and scholars attending academic institutions in the U. S. As sojourners in a foreign culture, Chinese students inevitably 
experience difficulties in their daily life and academic endeavors. The purpose of the thesis is to examine what are the specific situations that are perceived by Chinese students as stressful, how they cope with the situations, and whether there are correlations between the perceived stressors, coping strategies, and the academic performance of the Chinese students.

Seventy Chinese students attending schools of higher education in the greater Portland area responded to the 10-page 128-question survey in English. Data was collected through person-to-person contact. The Statistical Package for Social Science (SPSSX, 1988) was used to summarize the data statistically. The Pearson Product Moment Correlation was employed to identify correlations among variables. Results showed Chinese students ranked high in the perceived academic self-efficacy and they had high GPA. Six situations were identified as "more stressful" by the majority of Chinese students. Eleven coping strategies were identified as "oftenused" by Chinese students. One significant correlation occurred between the environmental stressors and the subjects' GPA.

In conclusion, the research revealed that Chinese students attending educational institutions in the U. S. face tremendous amounts of stress. The stress includes the traditional student pressure and the challenge of living in a different culture. Chinese students used certain culture specific coping strategies to deal with stress - Their patterns of coping behaviors are characterized as practical, self-effacing, less person-to-person involvement, and less verbal expressions of their problems. Implications for future study 
are suggested with emphasis on the design of intercultural communication training programs to prepare Chinese sojourners. 
COMMUNICATION STRESSORS AND COPING STRATEGIES AMONG CHINESE STUDENTS IN THE UNITED STATES

by

QIU LU LIANG

A thesis submitted in partial fulfillment of the requirements for the degree of

\author{
MASTER OF ARTS \\ in \\ SPEECH COMMUNICATION
}

Portland State University

1991 
TO THE OFFICE OF GRADUATE STUDIES:

The members of the Committee approve the thesis of Qiu $\mathrm{Lu}$ Liang presented November 1, 1990.

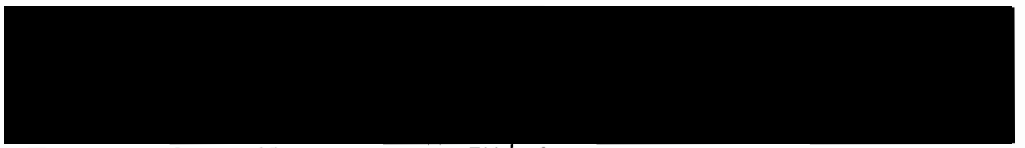

Devorah Liberman, Chair

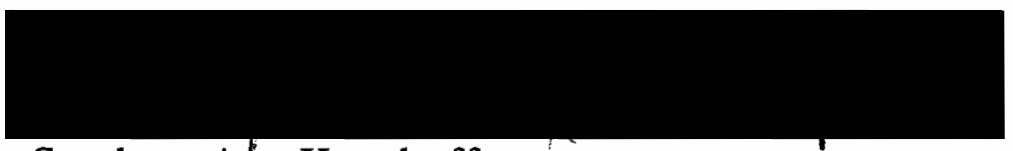

Stephen A? Kosokoff

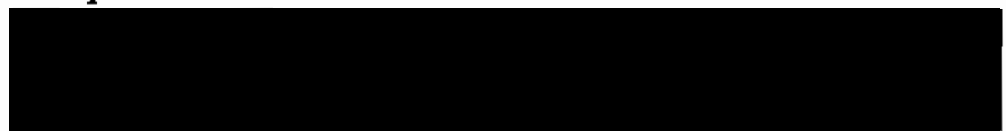

Robert- W. Vogelsang

Connie Dawson

APPROVED:

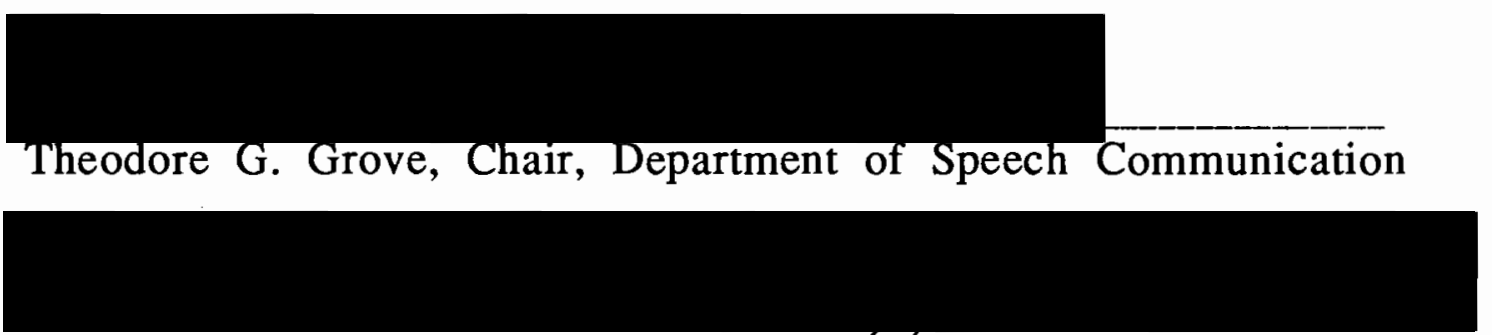

C. William Savery, Interim Vice Provost for Graduate Studies and Research 


\section{ACKNOWLEDGEMENTS}

Finishing a Master's thesis is a difficult process. Yet writing an acknowledgment is a more difficult task. The gratitude I have towards the many people is almost impossible to be adequately expressed in words.

I would like to thank the many friends and faculty in the Department of Speech Communication, and my committee members Dr. Lieberman, Dr. Kosokoff, Dr. Vogelsang, and Ms. Dawson for being so supportive all the time. I respect each of you for the intellectual inspiration you gave me, and your dedication to higher education. A special salute to Dr. Lieberman, an unusual professor and counselor very much loved by students, especially international students. Without your relentless help, encouragement, and academic advice, the completion of the thesis would be impossible.

Thanks to Atsuko Kurogi. Together we shared so much joy and bitterness of sojourning experiences; together we grew. I will always cherish our friendship. Thanks to Muneo for helping with the data, and Noriko Nakagawa, Mamie Jaroku, Simon Chen, Andrew Gess for all your encouragement and support. I owe much of my gratitude to the Chinese students in Portland area for their contributions in gathering the data. A very special thank goes to my dearest friends Jack Bennett and Linda Vick. Your support and acceptance of my whole person has meant a world of difference to me. Without your help, continuous encouragement, I would not have been able to do 
this at all. Words would not be enough to express how much I appreciate your friendship.

Last but not the least important, I would like to express my gratitude to my American family the Weidmans, and my family in China. Dear brothers and sisters, I love you all. This thesis is dedicated to my beloved parents $\mathrm{Mr}$. Chen-Chan Liang, and $\mathrm{Ms}$. Wushui who have loved me, raised me, and supported me in ways no other parents would have done better. To the persons named above and many others whose names may not have appeared, a simple but much meaningful THANK YOU! You are always on my mind. 


\section{TABLE OF CONTENTS}

PAGE

ACKNOWLEDGEMENTS iii

LIST OF TABLES xiii

\section{CHAPTER}

I INTRODUCTION. 1

Rationale 7

Significance. 7

Definitions. 8

\section{I LITERATURE REVIEW}

Culture and its function...................................................... 11

Cultural disparity and communication difficulty........... 12

Value differences between Chinese and American........ 14

Difference in communication styles................................. 17

Acculturation and stress................................................... 22

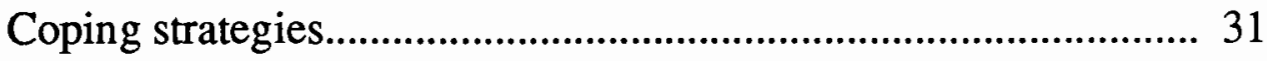

Training programs............................................................... 33

Perceived Academic Self-efficacy...................................... 35

Biodemographic variables................................................ 37

Purpose of study................................................................ 38

Research Questions.............................................................. 39 
Instrument......................................................................... 40

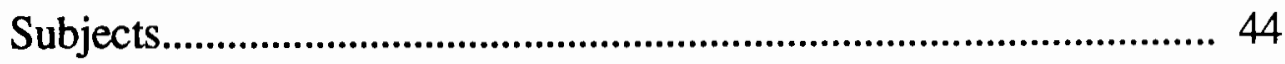

Procedure............................................................................... 44

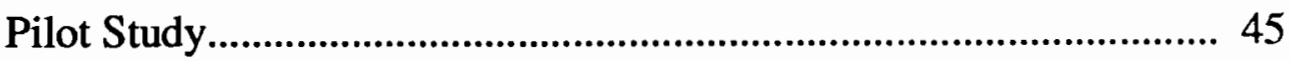

Statistical Analysis............................................................. 45

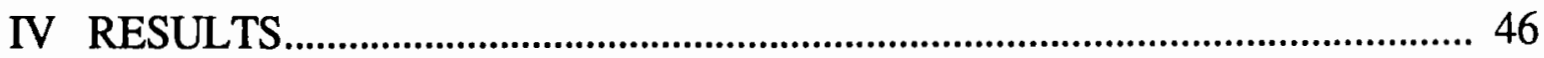

Biodemographic Variables................................................... 46

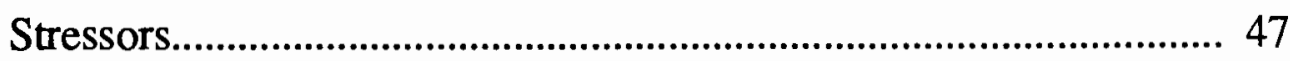

Coping Strategies..................................................................... 50

Significant Correlations........................................................ 51

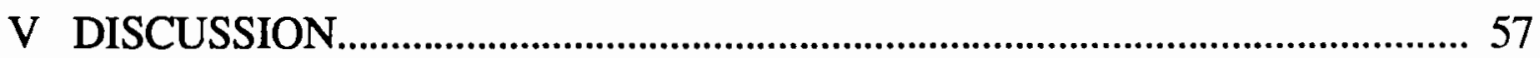

Results to Research Questions............................................ 57

Biodemographic Variables.................................................. 58

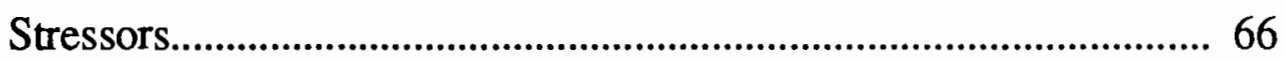

Coping Strategies..................................................................... 74

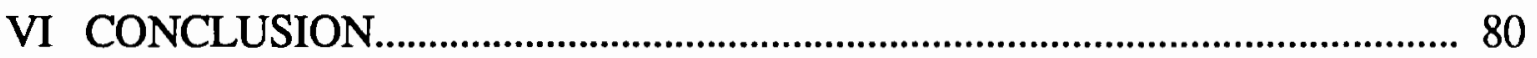

Summary of Research Results......................................... 80

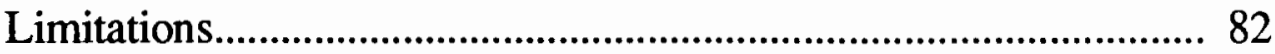

Implication for Future Study........................................ 86 
PAGE

\section{APPENDICES}

A BIODEMOGRAPHICS.................................................. 99

B STRSSORS CATEGORIZATION................................. 101

C COPING STRATEGIES CATEGORIZATION............... 105 


\section{LIST OF TABLES}

PAGE

\section{TABLE}

I "More Stressful” Stressors.........................................................49

I I “Often-Used” Coping Strategies................................................52

I I I "Not-Used" Coping Strategies...............................................53

IV Intercorrelations Among Biodemographic Variables........53

V Correlations Among Biodemographic Variables And Stressors

V 1 Intercorrelations Among Stressors...................................55

VII Intercorrelations Among Coping Strategies.......................56 


\section{CHAPTER I}

\section{INTRODUCTION}

The advancement of technology in transportation has provided easier access for persons to travel outside of their own countries and thus the flow of humans across national and cultural boundaries is more active than ever before. Worldwide, reasons vary why people relocate from country to country: e.g. tourism, business assignment, immigration, and education. Modern technology has enabled people to travel beyond their cultural and national boundaries. Meanwhile, the social and political reforms that have been taking place on a global scale had allowed more interactions between cultures. The world is becoming a global village. Following China's open-door policy in the late 70's and early 80's, there has been a significant increase in the number of Chinese students attending academic institutions in the U.S. (the number of Chinese students coming to the United States has declined a little bit since the Tianmen incident on June 4th 1989). There are approximately 26,000 Chinese students currently enrolled in institutions of higher education in the United States. (Institute of International Education, 1989, p. 152). Portland State University alone has approximately 100 Chinese students (Portland State University International Student Service, student statistics, Fall,1989). 
The increase of international students on campus means an increase in intercultural interaction. From an idealistic perspective, the cultural diversities brought by these students to the U.S. campus might be a positive move toward improving global communication. In the context of intercultural communication, the issue of cultural adjustment on the part of the sojourners becomes essential. Although the specific situation of international sojourners varies (i.e. reason for sojourn, and particular experiences), they all share the same characteristic: strangers in a foreign land amid the demands of a new life setting. As Kim and Gudykunst (1987) pointed out," Every stranger in a new culture must cope with a high level of uncertainty and unfamiliarity."

For sojourners in a new culture to survive and function effectively, they need to implement necessary skills to succeed at routine living: maintaining physical health and safety, earning an income, enjoying leisure activities, and developing relationships. Kim and Gudykunst (1987, pp. 8-9) labeled competence in maintaining basic survival necessities as "existential alertness." The development of competence in a different culture is the process of cultural adjustment.

Generally, sojourners face the challenges of acquiring "existential alertness." International students on the other hand, have to deal with another challenge: achieving academic goals. Attending educational institutions outside of one's home country represents a taxing situation in which the sojourning students are required to achieve "existential alertness" as well as "academic 
success." Usually, a high level of academic performance is a primary concern for international students. Sharma's 1973 survey among foreign students in North Carolina suggests that academic performance ranks highest in importance. Chinese culture places strong emphasis on education. Good academic performance brings "face" to a Chinese person. Since the ability to "save face" is the most basic and utmost objective for every Chinese (Hu,1944), good academic performance holds an especially important place for the Chinese students attending institutions overseas.

Interaction with people of the host culture provides channels for sojourners to learn about the new culture and adjust to it. Cultural adjustment is a process in which the sojourners learn new norms and rules of the host culture. It is a necessary and important process. However, this process is fraught with problems. In the process of communication, two kinds of messages are exchanged: verbal and nonverbal message. While most of our nonverbal messages are more subtle and we are less aware of the effects of nonverbal, greater attention is paid to the verbal, direct messages that are exchanged in the process of communication. The language barrier is often cited as the biggest difficulty for international students in their interaction with Americans, and in their academic endeavors (Cieslak, 1955; Bois,1956; Sellitz, Christ, Havel \& Cook 1963). There may be two reasons why language barrier poses as the biggest difficulty for international students. Pursuing an advanced degree requires tremendous amount of effort already. To pursue the degree in a foreign language adds more difficulty. Pursuing an 
advanced degree in English is an obstacle that every international student has to overcome. Second, there is relationship between our language and our perception. Sapir-Whorf hypothesis stated that the way we use language influences the way we think and behave.

Coming from a culture where English is not the native language, international students' ways of thinking and behavior may be influenced by their cultural origin. And language is a major part of cultural origin. Even though international students speak English, they may think and behave differently than their American counterparts. The differences in thinking and behaving between international students and the U.S. Americans add difficulty to the interaction between them.

Several authors have said that culture is the foundation of communication ( Porter \& Samovar, 1988; Hall, 1988). Culture teaches each individual how to communicate and relate to each other. This is the powerful process of enculturation. Since no two cultures are alike, each individual, regardless of his or her cultural origin, is enculturated with different values, beliefs, and different patterns in verbal and nonverbal communication. Because enculturation is such a slow and gradual process, what we are taught by our culture is not conscious or easily recognized. We often assume that since we are all human beings, we are all alike. We often are not aware of our own cultural values until they are contrasted by other cultural values that are different from our own. When persons from different cultural backgrounds interact with each other, basic cultural differences often emerge. Cultural differences affect the interaction process and 
possibly increase communication difficulty (Porter \& Samovar 1988).

When international students sojourn in a host culture, their lack of knowledge about host cultural values and appropriate social skills may increase communication difficulty. They may feel stressful because of the difficulty in communication with people in the host culture. Many studies have identified uncertainty of and unfamiliarity with another culture as a major cause of stress.

Lazarus (1969) pointed out that international sojourners experience stress during the process of cultural adjustment. Other studies (Barna, 1983; Furnham \& Bochner, 1986) indicated that stress experienced by international students affects these students' lives psychologically and physiologically, which in turn, may influence their academic performance.

Though many researchers have commented that stress affects international students, there is a paucity of intercultural communication literature which examines "communication stressors'" experienced by international students. Except for Dinges and Lieberman's 1989 research, and Atsuko Kurogi's 1990 research, current intercultural communication research has failed to examine the interrelated effects of sojourners' communication stressors, coping strategies, and academic performance. The question of what causes stress for students from particular cultures, how they cope with the stress, and if there is any relationship among the students' stress level, coping strategies, and academic performance remains relatively unexplored. 
Studies demonstrate that an individual's expectations of selfefficacy determines the initiation of coping behavior. Coping behavior is defined as effort adopted to overcome obstacles and achieving a desired goal (Bandura, 1977). In their 1989 research, Dinges and Lieberman surveyed international students from 32 countries. Their study suggested that perceived academic selfefficacy may influence stress level and coping behaviors of the international students. The results from the survey also suggested possible relationships between communication stressors, coping strategies, and academic performance among international students. They concluded that international students employ "coping strategies... to either obviate or decrease the impact of stressors." Dinges and Lieberman (1989) stated that examining subgroup differences based on the cultural origin of the students is important and needs further examination.

Possibly, Chinese students attending institutions of higher education in the United States may experience difficulty and stress in their interaction with peoples of the host culture. The present study examines what causes stress among Chinese students, the specific coping strategies employed by Chinese students to deal with the identified stressors, and correlations among stressors, coping behaviors, perceived academic self-efficacy, and academic performance. 


\section{RATIONALE}

It is important to examine possible correlations among Chinese students' communication stressors, coping strategies, perceived academic self-efficacy, and academic performance. By focusing on one specific cultural group--the Chinese students from Mainland China, the study will fill a void in the current research addressing communication stressors experienced by Chinese sojourners in the process of cultural adjustment. The data from this research will likely apply to a larger number of Chinese students attending universities in the United States. Because of the influence of the teaching of Confucianism, Chinese society has placed significant emphasis on education and intellectualism (Ching \& Prosen, 1980; Sue, 1973). Scholars and students are usually regarded as the treasure of the nation. The Chinese students studying overseas may eventually return to China. These students' contribution to China is expected by their countrymen to be significant. For this reason, these students' academic performance as well as their mental and physical well-being should not be ignored.

\section{SIGNIFICANCE}

The significance of this study is fivefold. First, the study of the Chinese students' communication stressors and coping strategies 
provides a step toward understanding the communication difficulties Chinese students experience, and toward identifying potential ways of dealing with stress. Second, examining the relationship between communication stressors and coping strategies can offer information for international student training programs. Third, the examination of the possible relationship among communication stressors, coping strategies and academic performance can provide Chinese institutions with useful information on how to design pre-departure training programs that will prepare Chinese students and scholars who are going overseas for education and research. Fourth, the information derived from this study can be used by those who interact professionally or personally with Chinese students, i.e. professors and faculty members, campus counselors, and academic advisors. Fifth, Chinese students who exhibit specific coping strategies for stress may also have higher perceived academic selfefficacy and better academic performance. If this is the case, the data concerning coping strategies may offer useful information to Chinese students overseas. This information can also be used by the helping professionals (instructors, administrative staff) in assisting Chinese students to achieve their desired academic goals.

\section{DEFINITIONS}

The following words or phrases are forthwith defined to aid with greater understanding of the thesis. 


\section{Stressor}

According to Lazarus (1971), stress is defined as the reaction to a stimulus depending on the individual's interpretation of the significance of a harmful, threatening or challenging event. A stressor is any stimulus that causes stress. Stressors are stimuli perceived by individuals as challenging or threatening in everyday interaction (Spradley \& Phillips,1972).

\section{Communication Stressor}

According to the interactional and psychological definition of stress (Lazarus, 1971), the act of communicating may be a stressor. Communication stressors are defined as any communication events which may arouse anxiety in the persons involved. Thus, when people interact, exchange verbal and nonverbal messages, and they perceive certain stress level from the interaction, the particular situation is a communication stressor.

\section{Coping strategies}

Coping strategies are defined as ways of dealing with stress. Coping strategies are behaviors that are perceived to either obviate or decrease the impact of stressors (Dinges \& Lieberman, 1989)

\section{Perceived academic self-efficacy}

According to Bandura (1977), self-efficacy is defined as the amount of effort one will expend and the length of time this effort will be sustained for one's achievement or performance. Selfefficacy influences the initiation of behaviors which are required to 
produce the desired outcome. Perceived academic self-efficacy is defined as the perceived expectations of self-efficacy to accomplish one's academic performance and achievement.

\section{GPA}

GPA stands for the accumulated grade point average. It is a measure of academic performance of the student. The accumulated grade point average of each student appears on an official grade report. The grade report is sent to the student at the end of each academic term. University registration office keeps records of GPA's of all the students enrolled. 


\section{CHAPTER II}

\section{LITERATURE REVIEW}

The purpose of this chapter is to examine the existing literature pertaining to the issues of stress, coping, and international students' academic performance. Theories about culture, and previous research in the areas of stress and coping, provide the basis for the present study. Part one of the chapter examines the function of culture. In this chapter, discussion focuses on the definition of culture, its functions, and its relationship to communication. Part two examines the issues of acculturation, stress, and international students' coping strategies used to deal with the stress.

\section{CULTURE AND ITS FUNCTION}

Culture is the environment around us. It is the system of appropriate behaviors that was taught to us in the process of socialization (Berger \& Luckmann, 1967). Brislin (1981, P. 51) stated: "Culture refers to those aspects of a society that all the members share, are familiar with, and pass on to the next generation." Culture is learned by observation and perception, without our seeking it out. Porter and Samovar (1982) defined culture as a pattern for living. "We learn to think, believe, feel, and strive for what [our] culture 
considers proper" (Porter \& Samovar, 1982, P.31). In other words, culture establishes a framework of acceptable behaviors within a specific cultural reality.

Culture plays a powerful, yet not easily recognizable, role in our lives. From birth, we absorb the values and patterns of behaviors from the people around us. Berger and Luckmann (1967, p. 281) told us that "the child takes on the significant others' rules and attitude, that is, internalizes them and makes them his own. Condon and Yousef (1979) stated, "Most of our behavior is outside our awareness so that 'normal behavior' means behavior according to the norms of our culture" (Condon \& Yousef, 1979, P. 34).

Pusch related that the "ways of thinking and perceiving are culturally conditioned rather than being universal aspects of human nature"(1981, p.7). It goes without saying that cultures differ since "culture is the unique life style of a particular group of people" (Harris \& Moran, 1982, p.64). This brief review suggests that culture is important in providing us with the framework through which we learn behaviors and interpret others' behaviors. Culture is shared, and cultures are uniquely different from each other.

\section{CULTURAL DISPARITY AND COMMUNICATON DIFFICULTY}

It is impossible to discuss communication, especially intercultural communication without mentioning "culture" since the two are inseparable. Porter and Samovar (1989, P.20) said that "Culture and communication are inseparable. Culture, consequently 
is the foundation of communication. And when cultures vary, communication practices also vary." Porter and Samovar further stated that culture not only determines who talks to whom; about what; and in what way; culture also dictates how communicative acts are received, interpreted, and sent (Porter \& Samovar, 1988, p. 32).

Since no two cultures are alike, it is inevitable that intercultural communication is more complicated and difficult because of the cultural differences. Several authors support the notion that intercultural communication is bound to be a difficult process. Triandis (1972) stated that the degree of cultural diversity correlates with the degree of difficulty in interaction. Furnham and Bochner (1982) said that the degree of difficulty in sojourners' everyday interaction is directly related to the cultural distance between the sojourner's home culture and the host culture.

Drawing from the results of a study on acculturative stress among Polynesian, Asian and American students on the Brigham Young University Hawaiian Campus, Graham (1983) supported the hypothesis that the greater the cultural differences that exist between the sojourners' home culture and the host culture, the greater their acculturative stress will be (Graham, 1983). Hofstedt's 1986 research on international organizations suggested that those from China and the U.S. differ significantly on the aspects of individualism, power distance, uncertainty avoidance, and masculinity/femininity. As Porter and Samovar pointed out, there is maximum cultural distance between 'Asians' and 'Westerners'. They also suggested that there is maximum communication disparity and 
difficulty between these two cultures (Porter \& Samovar, 1988).

While there is no substantive research indicating the exact disparity between American and Chinese cultures, it can be assumed that because of the vast cultural differences, Chinese students attending American universities may experience high stress and have great difficulty in interacting with people from the host culture. Graham's 1983 study identified that among the eight cultural groups on Brigham Young-Hawaiian Campus, Chinese felt the most exclusion and "un-loved" in the multicultural education setting. The differences in values and communication styles may be the factors that cause high stress and great difficulty in Chinese students' interactions with people from the host culture.

\section{VALUE DIFFERENCES BETWEEN CHINESE AND AMERICAN}

Psychologist Abraham Maslow (1968) constructed the need hierarchy which includes human needs that ascend in the following order: physiological survival (water, food, air, shelter, sex), safety, belongingness, self-esteem, and self-actualization. William Schutz's need theory explains that all human beings have these three social needs: inclusion, affection, and control (Schutz,1966). Both Maslow and Schutz's theories include the fundamental needs of human beings. However, regarding the definition of "needs," different cultures may have a different interpretation of the meaning of needs. What an American feels about belonging may be different than what 
a Chinese feels about belonging. Furthemore, the rank of importance in the need hierarchy, and the ways in which the needs are fulfilled may be different in Chinese culture and the U.S. culture.

Francis Hsu (1971. a) believed that we behave according to learned roles or rules in interpersonal relationships and according to an affective need for human intimacy. It is the fulfillment of this latter need that makes life meaningful, and makes cultures different. In the Chinese culture, individuals develop their affective bonds with immediate members of the family such as parents, siblings, or other close relatives. Chinese culture emphasizes that these bonds should be continuous so that the individual's self-esteem and future are tied to the family (Sue, 1977).

The Chinese family is a complex institution, and the roles of family members have long been rigidly defined. Chinese are taught to obey parents, to respect elders, and to create a good family name by outstanding achievement in some aspects of life i.e. academic or occupational success (Graham, 1983, p. 96; Sue, 1972, p.638). Any success or failure reflects on the family name. The family, in return for the member's loyalty and conformity, provides unconditional love and affection as well as moral support in time of crisis. It has been said that the Chinese tend to be family-oriented and Americans tend to be individualistic (Hofstedt, 1986).

The emphasis on formal education by the Chinese has been recognized by many investigators. Ching and Prosen (1980) observed that there is an intense commitment to education among the Chinese students. Graham $(1983$, p. 96) pointed out that Chinese 
emphasis is placed on:

(1) obtaining a good education (high [academic] achievement);

(2) obedience to parents;

(3) giving the family a good name.

Graham's finding in the 1983 study concluded that for the Chinese, "educational achievement was consistently valued above other types of achievement as reflected in the highest mean GPA on campus" (Graham, 1983, p.96).

Another issue that markedly distinguishes Chinese culture from American culture lies in the emphasis on "face-saving." Ching and Prosen (1980, p.229) pointed out that most cultural groups are adverse to embarrassment, but none go so far out of their way as the Chinese do to "save face." This concept of face-saving goes back to the ancient Confucian tenet of social propriety. For over 2,500 years, Confucianism has provided the dominant ideas and ideals for Chinese life (Scaff \& Ting, 1972, p. 648). The chief characteristic of Confucian philosophy is that life is orderly, with expectations of a person's behavior based on one's social position. Confucius described the social obligations of every person. The roles are: the relationships of ruler and subject, of parent and child, of husband and wife, of elder and younger brother, of friend and friend. For each of these relatioships there are proper behaviors. Thus, rulers act like rulers and subjects act like subjects. In the family, the father is the ruler, the wife and children are followers. Each person's role is clearly defined (Ching \& Prosen, 1980, p. 230). The slightest transgression from one's role by any member brings shame not only to the person, 
but also to the family name.

According to $\mathrm{Hu}$ (1944), the ability to "save face" is one of the most basic and utmost objectives of Chinese experience. The greatest humiliation a Chinese person may suffer is the "loss of face." The Chinese concept of "face-saving" relates to every aspect of life, i.e. harmonious interpersonal relationship, appropriate social behaviors, and achievement in academic performance or occupational success. $\mathrm{Hu}$ stated that the intensity of "face-saving" was such that a young person who failed to pass an examination might feel the shame so intensely as to commit suicide ( $\mathrm{Hu}, 1944, \mathrm{p} .48)$. Anyone who does not fulfill the responsibilities associated with his or her role will arouse doubts as to his or her competence and bring shame to self as well as to the family name (Hu, 1944, p.62). The concept of "facesaving" is internalized by a Chinese person through his her process of socialization. The concept acts as a social sanction that motivates Chinese behaviors. Since high academic achievement will bring "face" to a Chinese person, and "saving face" is so important to the Chinese, maintaining good academic performance becomes especially important for Chinese students. Thus, the cultural values of "facesaving" and academic success are interrelated.

\section{DIFFERENCE IN COMMUNICATION STYLES}

\section{High/low-context culture}

Edward Hall (1988) stated that there are basically two major 
communication styles: high context and low context. He said that "A high-context communication is one in which most of the information is either in the physical context or internalized in the person, while very little is in the coded, explicit, transmitted part of the message" (Hall, 1988, p.47). Low-context communication is just the opposite. In low-context communication, messages are explicit, most of the information comes from the coded, transmitted part of the message. (Hall, 1988, p.47).

The concept of high-context and low-context culture shows the differences in communication styles. Although no culture is exclusively at one end of the continuum, some cultures are more high-context while others are more low-context. Using the example of Chinese language and explaining how the language is utilized to convey meanings in social interaction, Hall said that "the need for context is experienced when looking up words in a Chinese dictionary.... For example, to find the word star, one must know that it appears under the sun radical. To be literate in Chinese, one has to be conversant with Chinese history. In addition, the spoken pronunciation system must be known, because there are four tones and a change of tone means a change in meaning" (Hall, 1988, p.47). Hall believed that American culture leans toward the low-context end of the continuum while Chinese culture leans toward the highcontext end of the continuum ( Hall, 1988, P.47).

Gudykunst and Nishida (1986) said that the level of context influences all other aspects of communication (p.527). Hall also said that "the level of context determines everything about the nature of 
the communication and is the foundation on which all subsequent behavior rests" (Hall, 1988, p.47). When interacting with each other, Chinese people send and receive messages in a more subtle way. In other words, Chinese rely on a great deal of the unspoken, the nonverbal aspects of the interaction. They may look for meanings and interpretation of the interaction from either the physical context ( i.e. time, setting), or the social psychological context ( i.e. social status, relationship, age difference, etc.) As classified as a lowcontext culture, interactions among Americans involve a great deal of verbal messages (either spoken or written). American interactants will pay much attention to the verbal messages. These differences in high-context Chinese culture and low-context American culture can be briefly summarized as nonverbal vs. verbal and indirect vs. direct. Further discussions will focus on the specific differences of the two communication styles represented by the two cultures.

Emphasis on nonverbal vs. verbal

Hall stated that verbal communication in a high-context culture does not carry as significant a message as nonverbal communication. On the other hand, more verbal messages are necessary for effective communication in a low-context culture. The Chinese have placed a significant emphasis on using nonverbal cues to send messages, and rely on nonverbal cues to interpret the meanings of interaction. While emphasizing the nonverbal aspect of communication, the Chinese seem to have aversion towards those who are verbally active. This emphasis is reflected in the many popular sayings in the 
culture. "Xing dong sen guo yu yen"-- actions speaks louder than words. This implies that what is spoken is not so important. What is more important and more meaningful is in one's action. "Seng shui bu xiang, xiang shui bu seng"-- deep water runs quietly, shallow water runs noisily. This saying is a popular metaphor that parents and teachers use quite often to teach children: those who remain calm may be the one who knows a lot and those who speak a lot may know very little. Another saying "Buan tong shei tang de heng"can be literarily translated into English as " the pail half full makes the most noise". Another saying is "Chu mang kan tian ce, jin mang kan lien ce"--when going out, look at the face of the sky, when going in the house, look at the face of the host/hostess-- indicates that to be socially appropriate, one need to look for facial cues of the host and hostess when one is interacting with him or her.

The listing of the Chinese sayings that emphasize action over words can go on and on. The point is clear that the Chinese consider that a wise and knowledgeable person is someone who acts more and speaks less. This emphasis on the action is also shown in their communication styles. Chinese tend to be quiet, not saying much, yet paying much attention to what is going on in the (context).

Indirect/ambiguous versus direct/explicit

The differences on the emphasis of verbal and nonverbal messages consequently leads to another set of communication styles that contrast each other in the two cultures. China is a high-context culture, much of the interpretations of interactions come from the 
nonverbal, unspoken aspects of the message. Chinese have been notoriously noticed for their ambiguity in expressing their thoughts and feelings. This is especially true when the thoughts and feelings may cause harm or "loss of face" to the persons involved.

As Murray (1988) observed: "The indirection that permeates Chinese speech can be particularly disconcerting to Americans. 'Maybe' and 'perhaps' are cultural stock-in-trade" (p. 98). "Maybe I am coming" can mean simply as "I am coming", or it can mean a polite refusal as "I am not coming." In either case when the person does come or does not come, no one loses face. The key point here is that the reader has to use the context to interpret what might be the appropriate answer behind that "maybe." For a Chinese person who is brought up in that reality and knows how to interpret the situation, it is not so difficult for him or her to act accordingly. Whereas, an American caught in the dilemma where a Chinese answer seems to imply some possibilities but never become materialized, may feel confused, or even cheated. This difference in an indirect versus direct communication style can cause misunderstanding and frustrations on the parts of both American and Chinese. The American might interpret the Chinese being indirect as a sign of "dishonesty," while the Chinese might perceive the Americans being direct as "rude" and "lacking social grace."

These major differences in communication styles, coupled with other differences in social norms, rules, and language barriers make interaction between Chinese and American a difficult process. Chinese students attending institutions of higher education in the 
United States may experience tremendous amounts of stress during their sojourn. Despite the fact that much research has been done to support the notion that there is a maximum cultural disparity between the U.S. and Chinese culture, little is known of how these cultural differences work its way into affecting the interaction process between the Chinese and American interactants.

\section{ACCULTURATION AND STRESS}

\section{Acculturation}

As reviewed earlier in this chapter, there are, in general, three characteristics of culture. First, culture is the totality of thinking, behaving, and life style. Second, culture provides a frame of reference with which the individual can understand and predict the world around him. Third, because culture is "the unique life style of a particular group of people" (Harris \& Moran, 1982, p. 64), all cultures differ. Some cultures may share many similarities, but inevitably, there is a distance between each and every culture. Culture plays a very important role in shaping our belief and value system, and in providing a framework for us to act and understand other's action. Through the continuous, unconscious interactions with each other, individuals undergo a progression of stages in which they integrate and internalize the numerous culturally acceptable concepts, attitudes, values, and norms. These cultural concepts, attitudes, values and norms become part of our own identity. This process of learning cultural patterns of thinking and behaving is 
termed "enculturation" (Kim, 1988). Because enculturation is a gradual and continuous process, what is enculturated into our belief system and what is internalized by us is usually unconscious, unrecognized, and remains unchallenged (Kim, 1988). The culture imprints may remain unquestioned until the individual relocates in a different cultural environment and encounters things that are quite different than one's own.

Because cultures are basically different, when an individual sojourns in a foreign country, he or she will inevitably experience something very different than in his/her home culture. The situations that are familiar, assumed, and taken-for-granted may not exist in the other culture. Even if the same situations exist in the other culture, they may not hold the same meanings. A great challenge confronts every sojourner: in a foreign land, strangers are subject to a greater or lesser degree to conform to the host culture. In order for them to function in a new culture, they may need to learn to use a new pattern of thinking and behaving. This process of learning and acquiring the elements of the host culture is called acculturation (Shibutani \& Kwan, 1965). In the process of acculturation, sojourners are re-enculturated into the host culture. This second-time enculturation is by no means as easy and smooth as the first-time enculturation. It is usually met with much resistance because it challenges the individual's original cultural identity which has been developed since early childhood.

Kim (1988) argued that for acculturation to occur, a person has to "deculturate" some of his or her cultural values and behaviors. 
While Kim says that the process of cultural-adaptation can be transforming and enriching to self-awareness and personal growth, she also purports that acculturation is a process wrought with stress and anxiety.

From the perspective of systems theory (Littlejohn, 1983), we can further understand why acculturation is such a stressful and difficult process. According to systems theory, human beings are regarded as an open system to the environment. Humans are characteristically homeostatic, attempting to hold constant a variety of variables in our internal meaning structure to achieve an ordered whole. This 'ordered whole' is the state of equilibrium. Culture is crucial in enabling us to maintain human equilibrium because it provides the frame of reference for each individual to organize information and make sense of the stimuli. When an individual receives stimuli that does not make sense within one's cultural frame of reference, such as the case when one goes to a foreign culture and encounters something deviant from the home culture, the system's equilibrium is disturbed. Stress confronts the individual. Uncertainty and unfamiliarity as the consequence of rapid change in environment are the major causes of stress (Kim, 1988).

Studies of sojourners and their cultural adaptation were stimulated by the post-Second World War boom in student exchanges and by the Peace Corps movement in the 1960's. Extensive literature described the sojourners' problems of psychological well-being in encountering unfamiliar environmental demands during their sojourning experiences. Some of the obvious 
environmental demands include the lack of language proficicency, change in diet, and loss of familiar nonverbal signs. (For extensive review of literature, see Brislin, 1981, Furnham \& Bochner, 1986; Landis \& Brislin 1983 ).

Though much has been examined regarding sojourners' acculturative stress and culture shock experiences, we know little about what specifically cause stress. In other words, what are the stressors experienced by a particular group of sojourners, and how do they deal with these stressors? These questions need to be explored.

\section{Acculturative Stress}

Acculturative stress refers to those individual states and behaviors that are mildly pathological and disruptive, including those problems of mental health and psychosomatic symptoms so often observed during rapid social change (Berry, 1979, p. 26). Though many efforts have been made to give a comprehensive definition of stress, all seem to have failed in giving an adequate definition (Fisher, 1986). Fisher, a noted researcher on stress, stated that stress exists when internal or external conditions deemed unpleasant cannot be changed. In other words, when an individual perceives an event as threatening and sees no or little control over the situation, stress arises. According to Fisher, stress is directly linked to the person's perception of control over the event.

Lazarus (1971) offered an interactional and psychological view of stress, pointing out that both the environment of stimuli and the 
reacting individual are crucial elements in stress. According to Lazarus and Folkman, stress is defined as "a particular relationship between the person and the environment that is appraised by the person as taxing, exceeding his or her resources and endangering his or her well-being"(Lazarus \& Folkman, 1984, p.19). Their definition of stress refers to a very broad class of problems because it deals with any demands which tax the human being's system. The definitions presented by Fisher, Lazarus and Folkman are similar in that they agree that stress is linked to the individual's perception of the situation. In their view, the event itself is merely a source of stress, or a stressor. It is the perception of how endangering the event is, and whether one has control over the event that determines the stress level. Thus, it is implied that for the same event, different individuals may perceive it as non-stressful, less stressful, or highly stressful.

Stress has also been called by many names: anxiety, anomie, conflict, uncertainty, frustration, and culture shock (Spradley,1972). One of the concepts most extensively discussed and investigated in the field of intercultural communication is 'culture shock'. With increasing cross-cultural interaction on a global level, and because "encounters with foreign cultural environment present surprises and uncertainties" (Kim, 1988), the idea that entering a new culture is potentially a confusing and disorienting experience has been amply discussed, written about, and researched. Oberg ( 1960) first defined culture shock as the "anxiety that results from losing all of our familiar signs and symbols of social intercourse"(p. 177). 
Empirical studies have suggested that stress and culture shock are significant variables in the understanding of acculturation. These earlier approaches to cross-cultural adaptation tended to view the experience of cultural adaptation and the stress that occurred during the process as problematic and negative (Kim, 1988). Countering this view, an alternative approach was proposed by Adler (1975), Ruben (1983), and Kim (1988). Adler reviewed culture shock and adjustment in a broader context of intercultural learning and growth. He regarded culture shock as a profound learning experience that leads to a high degree of self-awareness and personal growth. Similarly, Ruben (1983) asserted that culture shock experiences are the core or essence, though not necessarily the totality, of the crosscultural learning experience.

In her recent research concerning acculturation, Kim (1988) took a stress-adaptive-growth approach to acculturative stress. Stress-adaptive-growth implies that by going through the process of stress and adapting to it, an individual will learn and grow into a fuller person. Kim believes that stress is the natural consequence of cultural adaptation and, "it is this tension that is necessary for the continued existence of individuals facing environmental challenges" (Kim,1988, p. 54). According to Kim, adaptive transformation means the resolution of internal stress that promises the qualitative transformation of a person toward growth--a greater internal capacity to cope with various environmental conditions. Kim's stress-adaptation-growth approach views the acculturation process as dynamic, processual, and positive. 


\section{$\underline{\text { Stressor }}$}

It is important to distinguish between stress and stressor. Several authors (Fisher 1986; Lazarus, 1985; Lazarus \& Folkman,1984) have contented that stress exists in the cognitive process of the individual. Fisher (1986) advocated that the event (stressor) itself is not stress. It is the degree of control one can exert over the event that determines the stress level. If a person has total control of the situation, he or she may feel no stress. If the person sees very little or no control of the situation, he or she may experience greater degrees of stress. Thus, we can say that stress exists in our cognitive perception. Stress is a psychological state of being. On the other hand, a stressor is a source of stress. Any event or situation which is perceived by the individual as causing stressful feelings can be considered a stressor. By definition, stress is a subjective, psychological state of being. A stressor is the objective situation which is being cognitively perceived as causing stress. According to John Cassel (1970), there are specific factors which cause stress in social situations: when the outcome of important events is uncertain; when flight or fight are inappropriate coping mechanisms; when the outcome will be dependent upon constant vigilance; when aspirations are blocked; and when meaningful human interaction is restricted. In short, uncertainty, inappropriateness, fear, and restriction can be stressors. Rabkin and Struening (1976) analyzed stressors from a psychological perspective stating that "speed of change, prolonged exposure, lack of 
preparedness, and lack of prior experience have each been found to heighten the impact of stressful events" (Rabkin \& Struening, 1976, P. 1018).

Beck and Young (quoted in Graham 1983) stated that $78 \%$ of the students enrolled in American colleges suffered some symptoms of depression and stress. According to Beck and Young, the depression and stress were triggered by traditional student pressure such as failure to meet personal academic standards, the competitive edge, the need to define goals for life and career, and lack of social support network to fend off loneliness. In addition to these traditional student pressures, international students have to deal with the pressure of a language barrier and the stress brought by the rapid change in life style and social interaction patterns. As Barna (1983) stated, international students were often overwhelmed by a sense of helplessness, a threat to ego or self-esteem, inability to predict outcomes, loneliness, and social isolation during their stay in the United States.

Extensive research addressing culture shock identified uncertainty, unfamiliarity and unpredictability as major sources of stress. However, the research has not specified the particular stressors experienced by international students or any particular cultural group. Coming from a family-oriented, high-context culture and with the language system that is totally different, Chinese students may perceive certain stressors as highly stressful (e.g. missing the family atmosphere, speaking English, having to speak out in the classroom, talking to professors). Identifying the particular 
stressors Chinese students experience is the first step toward understanding their acculturation difficulties.

\section{$\underline{\text { Stress and Its Effects }}$}

Stress is a psychological state of being. It refers to a broad range of problems including psychological, social, and physiological demands which tax the human system (Lazarus, 1971). Though a more recent approach to stress research realizes that not all stress is bad, and that stress can be categorized as "distress"--stress that has negative impact, and "eustress"--stress that brings positive outcome. Still, the negative effects of stress arouse researchers' attention. Barna (1983) said that stress can cause all types of illness, psychological disturbances, and social maladjustment, including obesity and poor academic performance. According to Sharma's 1973 survey, 195 foreign students in North Carolina expressed that academic difficulties rank as the highest anxiety producers.

Symptoms of culture shock described by Oberg ( 1972) include irritability, compulsive sleeping, eating and drinking, helplessness, isolation, loneliness, and homesickness. These symptoms are likely to affect the students' academic performance. Graham (1983) conducted an interview with students at Brigham Young University Hawaii campus which revealed that the students' reacted to feelings of depressions by 1) not studying; 2) excessive sleeping; 3) spending more time on outside-study activities; and 4) speaking with their own cultural groups. Graham's research indicated the possibility that stress negatively affects academic performance. However, in the 
same study, Graham noticed that Chinese students who faced similar depression tended to concentrate on their academic goals, sublimating their problems. Thus, stress may not have negative effects on the Chinese students' academic performance. On the contrary, stress may positively correlate with the Chinese students' academic performance.

\section{COPING STRATEGIES}

Coping strategies, otherwise termed as defense mechanism, control, or mastery, refers to any of the methods that are employed to either "obviate or decrease the effect of stress" (Dinges \& Lieberman, 1989). Fisher (1986) believed that control initiated by individuals has adverse effect on negative stimulation. He further stated that there are mainly three ways of dealing with stress. First is the behavioral control defined in terms of "the availability of a response that can modify objective characteristics." Second is the cognitive control which involves the processing of relevant material to reduce stress. Third is the decisional control which refers to the choice between different possible courses of action (Fisher, 1986, p.27).

Various types of counseling and therapy as means of dealing with stress and problems have enjoyed wide popularity in western cultures while these coping methods are virtually unknown or even unheard of in Chinese culture. When American students have problems, they are likely to go to professional counselors and seek 
help from them (Portland State University, counseling and testing services, 1990). According to the report by Derald Sue (1977), a low percentage of Asian students used a campus counseling services. Sue speculated that in Asian cultures, people prefer to hide their personal problems rather than show them to the public. They will turn to family members for help first. The family is the primary, if not the only, source for support and help.

Another important reason why Chinese would not use a counseling service on campus is because in the Chinese culture, selfdiscipline and self-restraint is a sign of wisdom and personal strength. The Chinese believe that if you are strong and welldisciplined, your inner strength will have the power to solve the problems by yourself. Disclosing problems to others, especially to outsiders, is a sign of weakness and this feeling of weakness will lead to a "loss of face" both to the individual and his or her family (Ching \& Prosen, 1980). Thus, we can speculate that when stressful situations arise, Chinese will first try to solve the problem by himself/herself. The second source of help will come from family members or close friends. In the case of Chinese students in the United States, since majority of them do not have their immediate families near them, these Chinese students may rely on their close friends as support network.

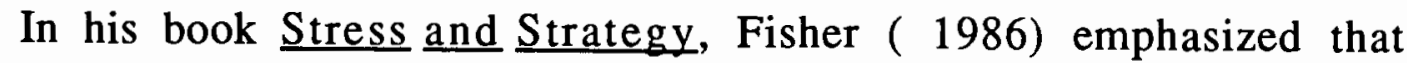
the presence or absence of control affects the response to stressful conditions. Fisher further pointed out that there are three ways of coping. First is the behavioral control defined in terms of "the 
availability of a response that can modify objective characteristics" (p.27). The second type of coping is cognitive control which involves the cognitive processing of relevant information to reduce stress. Decisional control is the third type of coping proposed by Fisher which refers to the choice between different possible courses of action. Basically, Fisher's coping mechanisms involve both interactional and psychological aspects of coping.

In line with Fisher's approaches, Lazarus (1979) suggested two coping strategies for international sojourners. One is preparatory coping that includes learning language and getting information about the country. The second is emotion-focused coping that consists of various defense mechanisms such as denial, intellectuallizing, and avoiding negative thoughts. Mechanic (1970) claimed that there are three ways to cope with stress: 1) instrumental (skills and capacities done by preparation such as information seeking, anticipatory problem solving, preparation of alternative strategies; 2) motivation; and 3) socio-emotional defenses. As summed up by Barna (1983, p.34), Lazarus' emotion-focused coping and Mechanic's socioemotional defense include attention deployment, defensive reappraisal, and wishful fantasies of relief.

\section{TRAINING PROGRAMS}

In addition to the coping strategies which are initiated by individuals, there are training programs that are organized and designed by institutions or trainers. Training programs are activities 
designed to train participants how to deal with certain stressful events. The program includes pre-departure training which is done in the home country, and orientation-training that is done after the sojourners arrive at the host country. Harris and Moran (1977) stated that it is important for intercultural sojourners to learn the verbal and nonverbal languages of the host culture.

Meichenbaum (1975) designed the "Inoculation Training" from a stress-management approach. The program, which is intended not to avoid stress but to manage stress, has three functions: educating people about the nature of stressful reactions; making people rehearse various coping behaviors; and giving them an opportunity to practice their learned coping skills in a stressful situation. Meichenbaum's training program takes an active and positive approach to stress-management which emphasizes that stress, when managed appropriately, can be a "eustress". Eustress is defined as stress that brings out positive outcome.

Triandis and Brislin (1988) designed a training program in which they divided cultures by individualistic and collectivistic characteristics. They defined collectivist culture as one where individuals are "allocentric", meaning that individuals pay more attention to the needs of a group. Individualistic culture is the one where individuals are "idiocentric", meaning that people pay more attention to their own individual needs than to the needs of the group. The authors categorized Africa, Asia, and Latin America as collectivist cultures and the U.S.A and Northwestern Europe as individualistic cultures. In the program, Triandis and Brislin also 
gave some concrete suggestions for persons of collectivistic cultures. When interacting with persons from individualistic culture, "expect the other to be more emotionally detached from events that occur in his or her ingroup than is likely in your culture" (Triandis \& Brislin, 1988, p.279); "Do not feel threatened if the other acts competitively" (Triandis \& Brislin, 1988, p.279). Their intercultural training program presents a new approach in which the focus is on culturespecific characteristics.

From the previous review, there are three major coping strategies to deal with stress:

1 ) services provided by professional counseling and therapy.

2) coping mechanisms initiated by individuals. The individually-initiated methods consist of behavioral control, cognitive control, and socioemotional defenses.

3) training programs organized and designed by trainers. The training programs include pre-departure training and orientation training.

A close look into some Chinese cultural and social factors such as: 1) prejudice against mental health service; 2) difficulty in selfdisclosure to outsider about personal problems; 3) emphasis on using internal strength to overcome difficulties, and 4) unawareness of intercultural communication and training programs provides us with the clue that the coping strategies most likely employed by Chinese students will be the coping methods initiated by individuals. It has been known that Chinese students are not likely to use campus 
counseling services (Sue, 1977; Ching \& Prosen, 1980). In times of difficulty, they may first try to solve problems by themselves. The Chinese cultural and social factors may characterize the coping strategies employed by Chinese students as uniquely culture-specific. Thus, what specific coping methods are employed by these students becomes an important question, yet to be answered.

\section{PERCEIVED ACADEMIC SELF-EFFICACY}

Bandura's self-efficacy theory advocates that "expectations of personal efficacy determine whether coping behavior will be initiated, how much effort will be expended, and how long it will be sustained in the face of obstacles" (1977, p. 191). In other words, Bandura believes that efficacy expectation is the conviction or motivation that leads the individual to initiate behaviors that are required to produce the desired outcomes. The presence or absence of this conviction, and the strength of this conviction is likely to affect the intensity of effort adopted by the individual to cope with given situation. In simpler words, self-efficacy influences choice of behaviors, such as the initiation and persistence of coping behaviors. (Bandura, 1977, p.193). In terms of perceived academic selfefficacy, this suggests that if a student has a low perceived academic selfefficacy concerning the completion of academic goals, he or she may put little effort into dealing with situations that are threatening to his or her goals. On the contrary, if a student has a high perceived academic self-efficacy, he or she may execute behaviors with 
stronger perseverance to cope with situations that are inhibiting his or her academic goals.

Applying Bandura's self-efflcacy theory in the study of Chinese students' coping behavior, it is suggested that students' academic expectations affect both their choice of action and intensity of effort adopted. According to Bandura, there may be a relationship between perceived academic self-efficacy, stressors, and coping strategies. But because the perception of stressors and the employment of coping strategies are complicated by some cultural and social factors, it is necessary to study the relationships among perceived academic self-efficacy, stressors, and coping strategies in one cultural group.

\section{BIODEMOGRAPHIC VARIABLES}

Individuals from one culture may share many similarities in their thinking and behaving. However, this does not imply that everyone from the same culture will think and act the same way. Differences in age, sex, educational background, and personal experiences are the factors that explain why people are not cultural robots. They do not think and act exactly the same even though they are from the same culture. Authors have recognized the individual diversity within the same culture. Furnham and Bochner (1982) classified three conditions causing culture shock: 1 ) cultural differences, 2) individual differences; 3) sojourn experiences.

Sojourn experiences (previous trips to the host country) and biodemographic variables (age, sex, education level, length of 
sojourning experience, size of social support network, previous training experience) need to be considered as possible factors influencing sojourners' intercultural experiences. Furnham (1987) emphasized that investigation of relevant cultural and individual differences in current intercultural communication research is important. Dinges and Lieberman ( 1989) surveyed 230 international students from eleven countries. Their research showed that there are possible relationships among stressors, coping strategies, and perceived academic self-efficacy. They suggested that it is important to examine subgroup differences based on the cultural origin of students, and to include biodemographic variables to incorporate a greater range of potential predictor which in term will help individuals achieve better adaptation.

\section{PURPOSE OF STUDY}

Based on the review of literature, the present research is intended to examine the relationships among communication stressors, perceived academic self-efficacy, academic performance, coping strategies, and biodemographic variables among the Chinese students attending institutions of higher education in the United States. 


\section{RESEARCHQUESTIONS}

Based on the previous review of intercultural communication, two research questions arise.

Research Question One: Are there relationships among biodemographic variables, communication stressors, coping strategies, perceived academic self-efficacy, and academic performance (GPA)?

Research Question Two: Is there greater reported stress associated with communication stressors than with other stressors? 
CHAPTER III

RESEARCH METHODS

This chapter describes the instrument used to generate data, the subjects, data collection procedure, the pilot study, and the statistical analysis used to analyze the data.

\section{INSTRUMENT}

The instrument used was a 10 page, 128 question survey. It was written in English and responded to by the subjects in English. The questionnaire was in English because Chinese university students have adequate understanding of the English language. As international students, Chinese students are required to pass the TOEFL (Test of English as Foreign Language) test before they are admitted to programs in the U.S. institutions of higher education. The instrument had four sections: 1) Demographic information; 2) Perceived academic self-efficacy; 3) Stressors (communicationstressors and non-communication-stressors); and 4) Coping strategies. The demographic information included age, gender, academic level (freshmen, sophomore, junior,senior, graduate, ESL, and visiting scholar), GPA, length of sojourn in the U.S., previous 
intercultural communication training experience, previous sojourn experience in the U.S., planned length of stay in the U.S, and number of close American friends (See Appendix A).

Bandura's (1977) scale of perceived self-efficacy was employed to measure the students' perceived academic self-efficacy. Students were asked to rate their own level of confidence in completing their academic goal. Using a 1 O-point Likert-type scale which ranged from most confident (10) to least confident (1), students answered three questions. The three questions were:

1 ) How confident are you in completing the academic term?

2) How confident are you in completing the academic year?

3 ) How confident are you in completing your degree?

Dinges and Lieberman's 1989 "Questionnaire of International Students' Stress and Coping" was used to measure the stress levels experienced by the Chinese students. The subjects read 49 situations they may encounter in their daily lives. On a 9-point Likert-type scale, they rated the level of stress perceived during each situation. They ranked their stress level in each situation from $O$ (no current stress) to 9 (highest degree of stress). If the subject had never encountered the situation and thus had no current stress, he or she left the item blank.

The 49 situations were classified into two categories: communication stressors and non-communication stressors. Communication stressors were classified thus because the situations involved interactions between students and other interactants. Communication stressors included: 1) in-class interaction (e.g. giving 
a class presentation, asking question in class); 2) social interactions (e.g. socializing over a meal, having an intimate relationship); 3) environment/university procedure (e.g. registering for classes, finding a place to live, buying textbooks). Non-communication stressors included academic performance (e.g. receiving a $D$ or $F$ on a test, studying for a test) and intrapersonal communication (e.g. being an international student, loneliness for other speaker of my native language). (See Appendix B for more details). Non-communication stressors were classified thus because those situations did not involve interaction with other interactants. The stressors were categorized into communication and non-communication stressors for the purpose of identifying whether there was a greater frequency of communication stressors than non-communication stressors reported.

Lazarus and Folkman's 1984 "Ways of Coping" was adapted to measure the frequency of Chinese students' coping strategies. When Lazarus and Folkman designed the scale, they suggested that process-oriented coping behaviors refer to specific thought, feelings, or acts rather than to what a person reports he or she might or would do. Thus, the scale was designed so that coping behaviors would be examined in a specific context. Also the scale intended to study ways of students' coping in slices of time so that changes could be observed as to what is thought, felt, and done as the requirements and appraisals of the encounters changed (Lazarus \& Folkman, 1984, p. 317).

The measurement consisted of eight submeasurements for different coping behaviors: 1) problem-focused coping (e.g. analyze 
the problem so as to understand it, or make a plan of action and follow it); 2) wishful-thinking coping (e.g. hope a miracle would happen); 3) Detachment coping ( e.g. try to forget the whole thing); 4) Seeking-emotional/social-support coping (e.g. talk to someone about how I feel); 5) focusing-on-the-positive coping (e.g. try to keep my options open, look for the positive aspects); 6) self-blame coping (e.g. criticize or lecture myself); 7) tension-reduction/relaxation coping (e.g. sleep more than usual, exercise); 8) keep-to-self coping (e.g. try to keep feelings to myself) (See Appendix C for more details). Lazarus and Folkman (1984, pp. 318-319) suggested that basically, there are two factors (problem-focused and emotionfocused factors) in coping strategies. The eight submeasurements could be categorized into two types of coping behaviors. One is the problem-focused orientation such as coming up with several solutions, gathering information, and making plans for action. The other is the emotion-focused orientation such as seeking emotional/social support, emphasizing the positive side of the situation, self-blame, detachment, and keeping things to self. Among the eight submeasurement, problem-focused coping has the characteristics of a problem-focused orientation while wishfulthinking, detachment, seeking-emotional/social-support, focusing on the positive, self-blame, tension-reduction-relaxation, and keepingself are characterized with a emotion-focused orientation. There were 67 coping behaviors suggested in the questionnaire. The students were instructed (with written instruction in English) to rate their frequency in employing each of 
the coping behaviors on a four point scale. $\mathrm{O}=$ not used, $\mathrm{l}=$ used somewhat, $2=$ used quite a bit, $3=$ used a great deal.

\section{SUBJECTS}

Seventy Chinese male and female students attending universities in the Portland area (mainly Portland State University, Oregon Health Sciences University, Lewis and Clark College) were asked to fill out the questionnaire. Of the seventy Chinese students, 46 were male and 24 were female.

\section{PROCEDURE}

Subjects were chosen through the reseacher's personal network, and with the the information (phone number and room number) obtained from the Chinese Students' Association Book. There were two ways in which the questionnaires were distributed and gathered. One was that the researcher made person-to-person contact with the majority of the subjects and asked them to fill out the questionnaire. The completion of each questionnaire usually took approximately thirty minutes. On some occasions, due to the time constraint, the researcher would come back a second time to the subject to pick up the completed questionnaire. Another way was through the network of researcher's friends. Friends of the researcher, who, through their personal network, distributed questionnaires to their friends and gathered the finished 
questionnaires in sealed envelopes.

Each student responded to the 10-page, 128-question survey in the English language. There were written instructions, in English, on how to fill each section of the survey.

\section{PILOT STUDY}

Prior to the distribution of surveys to the 70 subjects, a pilot study using the same instrument was conducted at Portland State University to test the reliability of the self-reported GPA by Chinese students. The results of the pilot study indicated that the Chinese students' self-reported GPA tended to be lower, though not significantly, than the official reported GPA.

\section{STATISTICAL ANALYSIS}

The Statistical Package for Social Sciences (SPSSX, 1988) was used to summarize the data statistically. The Pearson Product Moment Correlation was employed to identify correlations among the variables. 


\title{
CHAPTER IV
}

\author{
RESULTS
}

This chapter presents a summary of the data collected in the present research. First, the survey results will be presented in regard to biodemographic information, stressors that were perceived as "more stressful" or "less stressful," and coping behaviors that were "often-used" or "not-used." Second, correlations which emerged will be presented.

\section{BIODEMOGRAPHIC VARIABLES}

The total number of subjects participating in this study was seventy. The subjects consisted of 46 male $(66 \%)$ and 24 female (34\%) Chinese students. Subjects range in age from 21 to 41 -years old. The academic level of the subjects reported were: 2 Freshman (3\%), 3 Junior (4\%), 9 Senior (13\%), 5 ESL (7\%), and 48 Graduate (69\%). Twenty-three percent of the subjects reported their GPA between 2.51 and $3.0,37 \%$ percent of the subjects reported their GPA between 3.01 and $3.50,40 \%$ of the subjects reported their GPA between 3.51 and 4.0 .

For the length of sojourn in the U.S., 34\% of the subjects reported having stayed in the U.S. less than six months, $27 \%$ between 
six months and one year, 19\% reported between one to two years, and $20 \%$ have been in this country between three to five years. $64 \%$ of the subjects planned to continue staying in the U.S. for a period of one to five years, and $36 \%$ of the subjects planned to stay in the U.S. indefinitely. $99 \%$ of the subjects have had either no previous trip to the U.S. or have been to the U.S. only once. Seventy percent of the subjects reported no previous training in intercultural communication before coming to the U.S. The number of good American friends reported by each subject ranged from $O$ to 51 . The most frequently reported number of friends was 10.

As to the perceived academic self-efficacy, Chinese students ranked themselves particularly high. A moderate level of confidence is 5 on a 10 -point Likert-type scale. More than moderately confident means greater than 5 on the scale. $94 \%$ of the subjects ranked their confidence in completing the academic term (Spring, 1989) more than moderately confident. $93 \%$ had more than moderate confidence in completing their academic year, and $97 \%$ of the subjects were more than moderately confident about the completion of their academic degree.

\section{STRESSORS}

There were forty-nine situations presented in the questionnaire, each of which represented a situation that might be a stressor. The forty-nine stressors were classified as either communication stressors or non-communication stressors. Under the 
category of communication stressors were three types of situations: in-class interaction, social interaction, and environment/university procedures. Non-communication stressors included academic tasks and intrapersonal communication. The subjects were not told which was classified as a communication stressor or a non-communication stressor. Subjects ranked each stressor by using a scale of $O$ (no current stress) to 9 (highest degree of stress). When majority of respondents (larger than 55\%) reported their stress level between 5 and 9 , the situation was defined as more stressful. If the majority of respondents reported their stress level between $O$ and 4 , the situation was defined as less stressful. The other situations that were not responded to by a majority of the subjects was regarded as not significantly "more stressful" or "less stressful."

Six situations were identified as "more stressful" by the majority of Chinese subjects (See Table I). The "more stressful" situations are: Stressor number 5--acting as if I am from the United States, to gain acceptance from classmates; Stressor number 11 -. Pressure to get an A or B in a course; Stressor number 17--studying for a test; Stressor number 36--Discussing personal life problems with other students; Stressor 40--Being asked out on a date; and Stress number 43--socializing over a meal. Among these "more stressful" situations, four are communication stressors and two are noncommunication stressors. The 4 communication stressors are Stressor number 5 (57\%)--acting as if I am from the United States, to gain acceptance from classmates; Stressor number 36 (68\%)-discussing personal life problems with other students; Stressor 40 
(57\%)--asking someone out on a date; Stressor 43 (57\%)--responding to obvious negative remarks about my culture. The 2 non-

communication stressors are Stressor number 11 (59\%)--pressure to get an A or B in a course; Stressor number 17 (73\%)--studying for a test. Both of them are academic-task related stressors.

\section{TABLE I}

“MORE-STRESSFUL" STRESSORS

\begin{tabular}{|c|c|c|c|}
\hline $\begin{array}{l}\text { Stressor } \\
\text { Number }\end{array}$ & $\begin{array}{l}\text { Stressor } \\
\text { categorization }\end{array}$ & $\begin{array}{l}\text { Stressor } \\
\text { description } \\
\end{array}$ & $\begin{array}{l}\text { Percentage } \\
\text { of respondents }\end{array}$ \\
\hline$\# 5$ & $\begin{array}{l}\text { Comm/stressor } \\
\text { (in-class) }\end{array}$ & $\begin{array}{l}\text { "Acting as if I am from } \\
\text { the United States to gain } \\
\text { acceptance }\end{array}$ & $57 \%$ \\
\hline \#36 & $\begin{array}{l}\text { Comm/stressor } \\
\text { (social- } \\
\text { interaction) } \\
\end{array}$ & $\begin{array}{l}\text { "Discussing personal } \\
\text { problems with other } \\
\text { students." }\end{array}$ & $68 \%$ \\
\hline$\# 40$ & $\begin{array}{l}\text { Comm/stressor } \\
\text { (social- } \\
\text { interaction) }\end{array}$ & $\begin{array}{l}\text { "Being asked out on a } \\
\text { date." }\end{array}$ & $57 \%$ \\
\hline$\# 43$ & $\begin{array}{l}\text { Comm/stressor } \\
\text { (social- } \\
\text { interaction) }\end{array}$ & "Socializing over meal." & $57 \%$ \\
\hline$\# 11$ & $\begin{array}{l}\text { Non- } \\
\text { comm/stressor } \\
\text { (academic-task) }\end{array}$ & "Pressure to get a or B." & $59 \%$ \\
\hline \# 17 & $\begin{array}{l}\text { Non- } \\
\text { comm/stressor } \\
\text { (academic-task) }\end{array}$ & "Studying for a test." & $73 \%$ \\
\hline
\end{tabular}

Note: Situations are considered "more stressful" if subjects responded with a 5 or higher on a 9-point Likert-type scale.

Twenty-nine situations were identified as "less stressful" by the majority of Chinese subjects. Among the twenty-nine "less stressful" situations, three of them are non-communication stressors and twenty-six of them are communication stressors. The three "less stressful" non-communication stressors are Stressor number 1 (71\%) 
--being an international student; Stressor number 8 (63\%)-loneliness for other speakers of my native language; and Stressor number $15(75 \%)$--cheating on a test.

\section{COPING STRATEGIES}

There were sixty-seven coping strategies in the questionnaire and the subjects were instructed to rank the frequency of their use of these coping strategies on a scale of $O=$ not used to 1 =was used somewhat, 2=was used quite a bit, and 3 =was used a great deal. The coping strategies were categorized into eight subcategories:

problemfocused coping, wishful-thinking coping, seekingemotional/socialsupport coping, focusing-on-the-positive coping, self-blame coping, tension-reduction/relaxation coping, detachment coping, and keeping-to-self coping.

"Often-used" coping behaviors are defined as those that were ranked between 2 and 3 on the scale by the majority (greater than $55 \%)$ of Chinese students. Eleven strategies were identified by Chinese subjects as "used quite a bit" or "used a great deal" (See Table II). The eleven strategies are: Coping number 2 (84\%)--tried to analyze the problem in order to understand it better; Coping number 8 (58\%)--talked to someone to find out more about the situation; Coping number 10 (57\%)--kept my opinions open, leaving things somewhat open; Coping number 14 (56\%)--tried to keep my feelings to myself; Coping number 27 (61\%)--accepted the next best thing to 
what I wanted; Coping $30(58 \%)--1$ came out of the experience better than I went in; Coping $31(61 \%)$--talked to someone who could do something concrete about the problem; Coping 38 (56\%)-rediscovered what is important in life; Coping 61 (57\%)--I prepared myself for the worst; Coping 62 (56\%)--I went over in my mind what I would say or do; and Coping 64 (59\%)--I tried to see things from the other person's point of view (See Table II). Among the eleven "often-used" coping behaviors, three are the problem-focused coping, three are focusing-on-the-positive coping, two are keep-toself coping, two are seek-emotional/social-support coping, and one is wishful-thinking coping.

It was also noticed that there are six coping strategies that were not used by a significant number of Chinese students. The six coping strategies are Coping 22--got professional help; Coping number 33--tried to make myself feel better by eating, drinking or smoking; Coping number 34--took a big chance or did something very risky; Coping number 50--refused to believe it happened; Coping number 60--1 prayed; Coping 67--sought advice from a spiritual guide or tribal leader (See Table III).

\section{SIGNIFICANT CORRELATIONS}

Intercorrelations among biodemographic variables

The level of significance was set at $\mathrm{P}=<.01$. There are two significant intercorrelations among biodemographic variables. First, the academic level is negatively correlated with gender. Second, the 
TABLE II

“OFTEN-USED" COPING STRATEGIES

\begin{tabular}{|c|c|c|c|}
\hline Strategy Number & $\begin{array}{l}\text { Strategy } \\
\text { categorization }\end{array}$ & $\begin{array}{l}\text { Strategy } \\
\text { description }\end{array}$ & $\begin{array}{l}\text { Percentage of } \\
\text { respondents }\end{array}$ \\
\hline \#2 & $\begin{array}{l}\text { Problem-focused } \\
\text { coping }\end{array}$ & $\begin{array}{l}\text { "Tried to analyze } \\
\text { the problem." }\end{array}$ & $84 \%$ \\
\hline$\# 8$ & $\begin{array}{l}\text { seek-emotional- } \\
\text { social-support } \\
\text { coping }\end{array}$ & $\begin{array}{l}\text { "Talked to } \\
\text { someone." }\end{array}$ & $58 \%$ \\
\hline$\# 10$ & $\begin{array}{l}\text { Focusing-on-the- } \\
\text { positive coping }\end{array}$ & $\begin{array}{l}\text { "I kept my } \\
\text { opinions open." }\end{array}$ & $57 \%$ \\
\hline$\# 14$ & $\begin{array}{l}\text { Keep-to-self } \\
\text { coping }\end{array}$ & $\begin{array}{l}\text { "Tried to keep } \\
\text { feelings to } \\
\text { myself." }\end{array}$ & $56 \%$ \\
\hline$\# 27$ & $\begin{array}{l}\text { Focusing-on-the- } \\
\text { positive coping }\end{array}$ & $\begin{array}{l}\text { "Accepted the } \\
\text { next best thing." }\end{array}$ & $61 \%$ \\
\hline \#30 & $\begin{array}{l}\text { Keep-to-self } \\
\text { coping }\end{array}$ & $\begin{array}{l}\text { "Came out of the } \\
\text { experience better } \\
\text { than I went in." }\end{array}$ & $58 \%$ \\
\hline$\# 31$ & $\begin{array}{l}\text { seek-emotional- } \\
\text { social-support } \\
\text { coping }\end{array}$ & $\begin{array}{l}\text { "Talked to } \\
\text { someone who } \\
\text { could do } \\
\text { something } \\
\text { concrete about it." }\end{array}$ & $61 \%$ \\
\hline$\# 38$ & $\begin{array}{l}\text { Focusing-on-the- } \\
\text { positive coping }\end{array}$ & $\begin{array}{l}\text { "Rediscovered } \\
\text { what is important } \\
\text { in life." }\end{array}$ & $56 \%$ \\
\hline \#61 & $\begin{array}{l}\text { Wishful-thinking } \\
\text { coping }\end{array}$ & $\begin{array}{l}\text { "Prepared myself } \\
\text { for the worst." }\end{array}$ & $57 \%$ \\
\hline$\# 62$ & $\begin{array}{l}\text { Problem-focused } \\
\text { coping }\end{array}$ & $\begin{array}{l}\text { "I went over in } \\
\text { my mind what I } \\
\text { would do or say." }\end{array}$ & $56 \%$ \\
\hline$\# 64$ & $\begin{array}{l}\text { Problem-focused } \\
\text { coping }\end{array}$ & $\begin{array}{l}\text { "I tried to see } \\
\text { things from the } \\
\text { other person's } \\
\text { point of view." }\end{array}$ & $59 \%$ \\
\hline
\end{tabular}

Note: copings strategies are considered "often-used" if subjects responded with a 2 or 3 on the scale of 0 to 3 .

academic level is positively correlated with subjects' length of sojourn in the United States (See Table IV). 
TABLE III

"NOT-USED" COPING STRATEGIES

\begin{tabular}{|c|c|c|c|}
\hline Strategy Number & $\begin{array}{l}\text { Strategy } \\
\text { categorization }\end{array}$ & $\begin{array}{l}\text { strategy } \\
\text { description }\end{array}$ & $\begin{array}{l}\text { Percentage of } \\
\text { respondents }\end{array}$ \\
\hline \#33 & $\begin{array}{l}\text { Tension- } \\
\text { reduction coping }\end{array}$ & $\begin{array}{l}\text { "Tried to make } \\
\text { myself feel better } \\
\text { by eating, } \\
\text { drinking, } \\
\text { smoking." }\end{array}$ & $41 \%$ \\
\hline$\# 34$ & $\begin{array}{l}\text { Wishful-thinking } \\
\text { coping }\end{array}$ & $\begin{array}{l}\text { "Took a big } \\
\text { chance and did } \\
\text { something risky." }\end{array}$ & $50 \%$ \\
\hline \#50 & $\begin{array}{l}\text { Wishful-thinking } \\
\text { coping }\end{array}$ & $\begin{array}{l}\text { "Refused to } \\
\text { believe it } \\
\text { happened." }\end{array}$ & $48 \%$ \\
\hline$\# 60$ & $\begin{array}{l}\text { seek-emotional- } \\
\text { social-support } \\
\text { coping }\end{array}$ & "I prayed." & $42 \%$ \\
\hline$\# 67$ & $\begin{array}{l}\text { seek-emotional- } \\
\text { social-support } \\
\text { coping }\end{array}$ & $\begin{array}{l}\text { "I sought advice } \\
\text { from spiritual } \\
\text { guide or tribal } \\
\text { leader." }\end{array}$ & $55 \%$ \\
\hline
\end{tabular}

Note: Coping strategies are considered "not-used" if majority of students responded with a blank on the scale.

TABLE IV

INTERCORRELATIONS AMONG BIODEMOGRAPHIC VARIABLES

\begin{tabular}{|c|c|c|}
\hline Variable name & gender & $\begin{array}{l}\text { length of stay in } \\
\text { the U.S. }\end{array}$ \\
\hline $\begin{array}{ll}\text { academic level } \\
\\
\text { academic level } \\
\end{array}$ & $\begin{array}{l}-.7518 \\
\left(\begin{array}{c}.11 \\
p=.001\end{array}\right. \\
\end{array}$ & $\begin{array}{c}.8662 \\
\left(\begin{array}{c}.11 \\
p=.001\end{array}\right)\end{array}$ \\
\hline
\end{tabular}

Note: The significance level of correlation $\mathrm{p}<.001$

Correlation among the biodemographic variables and stressors

There is only one significant correlation between the biodemographic variables and stressors. The subjects' GPA's are 
negatively correlated with environmental stressors. There is no correlation between biodemographic variables and reported coping strategies (See Table V).

TABLE V

CORRELATIONS AMONG BIODEMOGRAPHIC VARIABLES AND STRESSORS

\begin{tabular}{|l|l|l|}
\hline Variable name & gende $r$ & $\begin{array}{l}\text { length of stay in } \\
\text { the U.S. }\end{array}$ \\
\hline & -.7518 & $\begin{array}{c}.8662 \\
.11) \\
\mathrm{p}=.001\end{array}$ \\
\hline
\end{tabular}

Note: The significance level of correlation $p<.001$

\section{Intercorrelations among stressors}

Seven significant intercorrelations emerged among the reported stressors (See Table VI).

All significant intercorrelations among stressors are positive. They are: 1) the reported academic stressors positively correlated with reported in-class interaction stressors; 2) the reported academic stressors positively correlated with reported social interaction stressors; 3) the reported academic stressors positively correlated with the reported environment/ procedure stressors; 4) the reported in-class interaction stressors positively correlated with the reported social interaction stressors; 5) the reported in-class interaction stressors positively correlated with the reported environment/ procedure stressors; 6) the reported social interaction stressors 
positively correlated with the reported environment/procedure stressors; 7) the reported intrapersonal stressors positively correlated with the reported social interaction stressors.

TABLE VI

INTERCORRELATIONS AMONG STRESSORS

\begin{tabular}{|l|l|l|l|}
\hline variable name & $\begin{array}{l}\text { academic-task } \\
\text { stressors }\end{array}$ & Social stressors & $\begin{array}{l}\text { environmental } \\
\text { stressors }\end{array}$ \\
\hline $\begin{array}{l}\text { inclass } \\
\text { interaction } \\
\text { stressors }\end{array}$ & $\begin{array}{l}.9320 \\
(.11) \\
\mathrm{p}=.000\end{array}$ & $\begin{array}{l}.8588 \\
.11) \\
\mathrm{p}=.000\end{array}$ & $\begin{array}{l}.8508 \\
.11) \\
\mathrm{p}=.000\end{array}$ \\
\hline social stressor & $\begin{array}{l}.8240 \\
(.11)\end{array}$ & & $\begin{array}{c}.85961 \\
.11) \\
\mathrm{p}=.000\end{array}$ \\
\hline $\begin{array}{l}\mathrm{p}=.001 \\
\text { academic-task } \\
\text { stressor }\end{array}$ & & & $\begin{array}{c}.8832 \\
.11) \\
\mathrm{p}=.000\end{array}$ \\
\hline $\begin{array}{l}\text { intrapersonal } \\
\text { stressors }\end{array}$ & & $\begin{array}{l}.9320 \\
(.11)\end{array}$ & \\
\hline
\end{tabular}

Note: The significance level of correlation $\mathrm{p}<.001$

Intercorrelations among coping strategies

Four intercorrelations emerged among the reported coping strategies (See Table VII). All intercorrelations are positive. They are: 1 ) the reported keep-to-self coping strategies positively correlated with the reported detachment coping strategies; 2) the reported keep-to-self coping strategies positively correlated with the reported seek-support coping strategies; 3) the reported self-blame coping strategies positively correlated with the reported seeksupport coping strategies; 4) the reported self-blame coping strategies positively correlated with the reported focusing-on- 
thepositive coping strategies. The many intercorrelations among coping strategies may suggest that these coping strategies share many common characteristics. There is no significant correlation between biodemographic variables and coping strategies. Also, coping strategies are not significantly correlated with stressors.

\section{TABLE VII}

INTERCORRELATIONS AMONG COPING STRATEGIES

\begin{tabular}{|l|l|l|l|}
\hline variable name & $\begin{array}{l}\text { academic-task } \\
\text { stressors }\end{array}$ & Social stressors & $\begin{array}{l}\text { environmental } \\
\text { stressors }\end{array}$ \\
\hline $\begin{array}{l}\text { Seek-support } \\
\text { coping strategies }\end{array}$ & $\begin{array}{l}.8894 \\
.11) \\
\mathrm{p}=.001\end{array}$ & $\begin{array}{c}.8170 \\
.11) \\
\mathrm{p}=.001\end{array}$ & $\begin{array}{l}.8882 \\
.11) \\
\mathrm{p}=.000\end{array}$ \\
\hline $\begin{array}{l}\text { self-blame coping } \\
\text { strategies }\end{array}$ & & $\begin{array}{l}.8276 \\
(.11) \\
\mathrm{p}=.001\end{array}$ \\
\hline
\end{tabular}

Note: The significance level of correlation $\mathrm{p}<.001$

To sum up the results, only one significant correlation emerged between stressors and biodemographic variables (GPA is negatively correlated with environment/procedure stressor). However, two intercorrelations exist among biodemographic variables. Seven intercorrelations emerged among stressors and four intercorrelations occurred among coping strategies. 


\section{CHAPTER V}

\section{DISCUSSION}

In this chapter, the research results will be discussed in relation to Chinese cultural values. First, biodemographic variables will be examined. Second, the stressors that were reporeted by Chinese subjects as "more stressful" and "less stressful" will be analyzed in relation to Chinese culture. Discussion will address the issue why certain stressors were reported by subjects as "more stressful" than others. Third, the researcher will identify patterns of coping behaviors reported by the Chinese subjects.

\section{RESULTS TO RESEARCH QUESTIONS}

Research Question One: Are there relationships among biodemogrphic variables, communication stressors, coping strategies, perceived academic self-efficacy, and academic performance?

Four findings emerged from the data pertaining to Research Question One. First, there was a relationship between biodemographic variables and communication stressors. GPA is one of the biodemographic variables. Chinese students' GPA's were negatively correlated with the environment/procedure stressors. Second, there were no significant correlations between 
biodemographic variables and coping strategies. Third, there was no significant correlation between communication stressors and coping strategies. Fourth, perceived academic self-efficacy was not significantly correlated with student's academic performance.

Research Question Two: Is there greater reported stress associated with communication stressors than other noncommunication stressors?

There was no greater reported stress associated with communication stressors than other non-communication stressors. Actually, among the six stressors that were perceived as "more stressful" by majority of Chinese students, three of them were communication stressors and three of them were non-communication stressors. This finding suggests that of the six stressors that were perceived as "more stressful," there was no indication that greater stress is associated with communication stressors.

\section{BIODEMOGRAPHIC VARIABLES}

Several interesting findings occurred among the biodemographic variables. First, the self-reported GPA among Chinese students is high. Sixty-two percent of the subjects reported their GPA as between 3.01 and 4.00. The high GPA suggests that Chinese students are successful in their academic pursuit. The finding in this research agrees with the finding in Graham's 1983 study which reported that Chinese were academically the most successful group, with the highest GPA mean on Brigham Young 
Hawaiian-Campus.

The reported high GPA among Chinese students raises an interesting point. In the Pilot Study conducted prior to the actual research, the results of the Pilot study indicated that the GPA reported by the Chinese subjects involved was between 3.20 and 3.88. Also, the Pilot Study suggested that Chinese were modest in estimating their personal academic success (as indicated by the fact that the official GPA of the subjects involved were actually higher than the self-reported GPA).

Modesty, as opposed to aggressiveness, is a cultural value strongly emphasized in Chinese society. Confucian teachings have been regarded as the ideals for Chinese culture for more than two thousand and five hundred years (Scarff \& Ting, 1972). The center stage in almost all approaches to Chinese social behaviors is commanded by chung-ni K'ung or Confucius, as he is known in the West. Scholars contented that the philosophy of Confucianism is greatly influenced by Confucius' own personal life (King \& Bond, 1985). Confucius was born in the town of Chou, a part of the kingdom of $\mathrm{Lu}$, in $551 \mathrm{BC}$. This was during the time of Chun Chiu when China was not a united country, a time of political instability in the Eastern Chou Dynasty, with the various kingdoms contending against one another for pre-eminence. These unsettling events directly impinged on the lifes of Confucius, as he moved in and out of political appointments with the ebb and flow of political fortune. Imparted with the personal experience of such chaotic social sufferings, Confucius' works and ethics have a fundamental concern 
for achieving social harmony within hierarchy.

Modesty becomes a very important virtue to be valued and adopted by citizens if they want to achieve harmony in a hierarchical society. The basic tenet of Confucian teaching dictates that every one in the society assumes a particular role which is associated with a set of appropriate behaviors. The orderly state of society or family (which is the ultimate goal for any civilized culture) is achieved on the basis that everyone adheres to his or her role and obeys the authority, without any transgression. Thus, ruler acts like a ruler and subject like subject.

The fundamental Confucian assumption is that man exists in relationship to others (King \& Bond, 1985). In Chinese culture, man is considered as a "relational being," socially situated and defined within an interactive context. A person who is superior in one context (i.e. he is the father and is the authority figure in the household) can be inferior in another context (i.e. he is the son to someone, or he is the younger brother to someone). Thus, to maintain harmony within social hierarchy, it is important that each person remains modest in all circumstances. Any transgression, or behaviors that violate one's role and status are not tolerated. According to Confucius, there are seven basic virtues: Ren (kindness), Yi (righteousness), Li (courteous ritual), Xing (honesty), Xiao (filial piety), Ti (brotherly love), Xien (modesty). "Jun Zi"--a refined gentleman--should possess these seven virtues in order to be respected by others. While the acquisition of all these seven virtues is the goal for the more upper-class gentleman, modesty is the one 
virtue that the general public should try to obtain. This cultural value is reflected in the popular sayings in China: "The nail that sticks out is hammered," "the first bird flies out of the wood will be shot;" "Be modest, and do not be proud, you will make great progress".

Since modesty is such a strongly emphasized cultural value, one would speculate that the perceived academic self-efficacy among Chinese would be low. However, when asked to rank their perceived academic self-efficacy, Chinese students ranked particularly high. Ninety-four percent of the Chinese students ranked their confidence in completing the academic term (Spring, 1989) more than moderately confident (greater than 5 on a Likert-type scale). Ninety-three percent had more than moderate confidence in completing their academic year, and nine-seven percent of the subjects were more than moderately confident about the completion of their academic degree.

Though there was no significant correlation found between biodemographic variables and coping strategies, it seems that the Chinese students may use positive self-efficacy as a coping strategy. They set up high expectations for their academic performance. This high expectation executes behaviors that will motivate and lead them to academic success. As Bandura's self-efficacy theory (1977) pointed out, expectations of personal efficacy determine how much effort will be expended and sustained in order to achieve a desired goal. In terms of perceived academic self-efficacy, this means that students with high self-efficacy will initiate behaviors, sustain those behaviors 
with stronger perseverance, to cope with situations that are interfering with their academic pursuit.

It may appear inconsistent that while Chinese are being modest in evaluating personal success, they would rank themselves high in their academic self-efficacy. Nevertheless, if we view their high selfefficacy as a means of coping, we can understand the myth of their high perceived academic self-efficacy. As Graham pointed out in his 1983 study, Chinese students have strong orientation to committed educational goals (p.92). He further pointed out that while aother cultural group (Samoans) would participate in more social activities in times of stress, "if Chinese were experiencing stress due to academic deficiencies, they would stoically commit themselves to more study time and less social activity" (p.96). This suggests that in times of stress, Chinese students would not turn to social activities as remedy to cope with stress. Instead, they would study more as a means of coping with stress.

Since modesty is characteristic of Chinese values, why would Chinese students go against their nature of being modest and rank themselves high in their perceived academic self-efficacy? One possible explanation is that the Chinese students use academic selfefficacy as a coping strategy. By setting up high expectations for their academic expectations, Chinese students would devote more time to their studies and shift their attention away from some situations that might cause high levels of stress.

GPA was negatively correlated with environment/procedure stressors. This suggests that those who have lower GPA may 
perceive the environment/procedure stressors as "more stressful" and those with higher GPA may perceive the environment/procedure stressors as "less stressful". The environment/procedure stressors included: 1 ) making child care arrangement; 2) asking people about university policies, rules, and services; 3) registering for classes; 4) using public transportation; 5) finding a place to live; 6) asking for career/professional advice from faculty and school staff; 7) buying textbook; 8) getting needed health care; 9) ordering food on campus. Since these environment/procedure stressors involve interactions with other people, several factors may be the explanations why GPA is negatively correlated with environment/procedure stressors.

First, the lack of English language proficiency may be the major factor. As Graham (1983) reported: "Of all the stress factors in the acculturative process, language proficiency appears to be the most critical. Chinese expressed insecurity through the lack of language proficiency" (Graham, 1983, p.90). If a student's English is not so good, he or she may not understand the information about policies, rules, and services available to them. Also, someone who is less fluent in English may feel insecure and have more difficulty in asking questions or asking for help from people of the host culture.

Secondly, uncertainty and unfamiliarity with the environment /procedure stressors may be another factor that explains why these situations can be stressful. The lack of previous intercultural communication training may be leading to the uncertainty and unfamiliarity about the environment/procedure situations. Seventy percent of the subjects reported that they had no previous training 
in intercultural communication. Lack of intercultural training may give sojourners little or no knowledge about the host culture. When faced with situations in which one has little knowledge about what to do, those situations inevitably become "more stressful."

Also, the differences in communication styles between China and U. S cultures become another stumbling block for the Chinese students to understand the environment/procedure situations. In a more high-context culture, most of the information about approriate social behavior is in the context, much of the learning about appropriate behaviors is achieved by observing others, rather than reading the rules and policies from the book. Thus, Chinese students are not accustomed to looking for written information to understand what to do. Yet contrary to the Chinese communication style and being a more low-context culture, information transmission in the American culture is more explicit and written out in words on papers. Most of the U.S. universities write out policies and procedures in catalogs and brochures. To understand the environment and university procedures, Chinese students need to know where to look for the information and how to understand these information. Without proper training, Chinese students will find it difficult to deal with the environment/procedure situations.

Besides, most of the environment/procedure stressors represent basic needs in a student's life i.e. ordering food; buying textbook; asking questions about policies; finding a place to live; getting needed health care; asking for career/professional advice from faculty and school staff; and registering for classes. When these 
basic needs are not satisfactorily met, students may not be able to concentrate on their studies and their GPA's may suffer. Though the researcher does not intend to imply that there is a causal relationship between environment/procedure stressor and GPA, it seems possible that when students are not adequately prepared to deal with the environment/procedure situations, their academic performance may be affected.

Third, ways of dealing with those particular environment/ procedure situations are very different in Chinese and U.S. cultures. In Chinese universities, all classes are assigned to students and textbooks are ordered by school administration. There is no need to register for classes. All students live in the school dormitories, thus the trouble of finding places to live and using public transportation to go to school are eliminated. Students in Chinese universities do not have to deal with the environment/procedure situations. On the contrary, in American universities, students have to take care of those matters by themselves. The environment/procedure situations are basic routines of American university students. There are certain policies and rules regarding the process of dealing with these matters. With no previous experience and insufficient training, in addition to the lack of language ability to inquire about these policies, Chinese students may find the handling of these environment/ procedure situations difficult and "more stressful." 


\section{STRESSORS}

Subjects were asked to respond to 49 situations in the questionnaire. Of the 49 situations, six situations were identified as "more stressful" by the majority of the Chinese students. The "more stressful" situations for the Chinese are: Stressor \#S--acting as if I am from the United States, to gain acceptance from non-international classmates; Stressor \#11--pressure to get an A or B in a course; Stressor \#17--studying for a test; Stressor \#36--discussing personal life problems with other students; Stressor \#40--being asked out on a date; Stressor \#43--socializing over a meal. Of the six "more stressful" situations, two were the academic-task related stressors, three were the social-interaction stressors and one was the in-class interaction stressor.

First, let's look at the academic-task stressors. "Getting an A or B in a course," and "studying for test" were perceived by majority of Chinese students as "more stressful". As mentioned in Chapter II, Chinese students have a strong commitment to high academic performance. This commitment to academic success is related to the cultural values of "face-saving" and "bringing good name to the family". Because the Chinese put much importance on "saving-face" and "bringing good name to the family," if a student succeeds in his or her academic performance, both the individual and the family name are honored by everyone in the society. If a person fails in the academic endeavor, he or she may be perceived ill by the society. As Graham (1983) noted, the intensity of Chinese students' commitment 
to succeed academically appears to stem from a fear of being perceived ill by home culture members. The concept of "bringing face to the family name" and the fear of "losing face" keep the students striving hard in their school performance. The cultural social value pushes the students to succeed in their academic performance. The need to succeed in formal education becomes the top priority for Chinese students. Because the fear of "losing face" associated with failure in school is so great, the academic task related stressors are likely to be the potential to trigger stress in Chinese students. It is easy to understand why Chinese students would perceive "getting an $\mathrm{A}$ or $\mathrm{B}$ " and "studying for a test" as "more stressful".

Second, let's examine why certain communication stressors (social interaction and in-class interaction) were perceived by Chinese students as "more stressful". The three social interaction stressors are: 1) Being asked out on a date; 2) Socializing over the meal; and 3) Discussing personal life problems with other students. Because of the strong emphasis on education, many Chinese students in the U.S. sacrifice their personal life to the commitment of formal education. They delay marriage and family planning. From my personal experience and observation during my contact with the Chinese students in Portland area, most of the students are single. They lead a life that is purely academic, with limited social activities and little time for personal pleasure. In Chinese society, marriage and family planning is regarded as the necessary process that everyone will go through. Confucius said that "Shan shi er li, chi shi 
er bu huo"--establish your family by the age of thirty, establish your career by the age of forty. The majority $(60 \%)$ of Chinese students in the survey fell in the age range of 25 to 30 which is the suitable age range for marriage. Chinese students are between the pull of two needs: to concentrate on success in academic pursuit, and to consider marriage and family planning. Both needs are important to the students, yet meeting these two needs demands attention and effort from the students. Being asked out on a date draws out the conflict between academic pursuit and personal life.

As for the stressor " socializing over the meal," the lack of previous training, and the lack of knowledge about what is the appropriate social interaction behaviors over a meal may be the reasons why the situation can be stressful.

Abbot (1970) commented that the Chinese culture values selfcontrol, and inhibition of strong feelings. Self-effacement rather than confrontation is a model of refinement for Chinese people. For a Chinese, "Sh iu Xin Yang Xin"--the cultivation of inner strength (i.e. morality, tolerance, enlightenment etc.) is the ultimate purpose of education and it is a life-long process of personal refinement. Chinese believe that inner strength and resource will overcome problems. If internal strength cannot overcome the problem, any external help is temporary or useless. For a person who lacks inner strength is likely to be overwhelmed and ask for external help again when crisis arises once more (Sue, 1972). The internalized value on self-control and inhibition of feelings makes it difficult for Chinese students to disclose themselves to others. 
The Chinese concept of humility may be another reason that explains why it is hard for the Chinese students to seek external help and discuss personal problems with other people. This concept of humility is interrelated with the Chinese belief that one's inner strength should be able to overcome problems. Ching and Prosen (1980) said that Chinese people feel a strong sense of shame and humility when they perceive some personal problems. Because "personal problems suggest a weak moral fiber, seeking outside help is tantamount to advertising personal failure" (Ching \& Prosen, 1980, p.229). With these cultural beliefs about inner strength, and the concept of shame and humility being internalized, a Chinese person, when encountering some problems, would first try to solve the problems with his or her inner strength. $\mathrm{He}$ or she would analyze the problems, accept what has happened, and think of what to do next time when a similar situation arises. If he or she cannot solve the problems, the person would at least try to hide the problems from the public so as not to draw shame to him/herself. It is unusual that a Chinese person would seek professional help for personal problems. Several researchers have reported that the Chinese tend to underuse mental health services available on campus (Sue \& Kirk, 1975, Kitano, 1976, Ching \& Prosen, 1980). The statistics citing the limited use of mental health services by Chinese students is indicative of their particular ways of dealing with personal problems. The Chinese cultural and social values on self-control, self-effacement, inhibition of strong feelings, and their concept of humility are the major reasons why "discussing personal life 
problems with other students" was perceived as "more stressful" for Chinese students.

Another communication-related situation that presents high stress level for Chinese students is "acting as if I am from the United States to gain acceptance from non-international students." This situation is related to the issue of acculturation and stress. Coming from a society that is collectivistic and family-oriented, the need to be accepted and to belong to a group is especially important for Chinese people. The Chinese saying "shei Xian Zu Shu" ... which is similar to the English saying that "act as the Romans do when you are in Rome" indicates that the Chinese have desire to conform/adapt to new behaviors in order to be accepted in a new environment.

In studying the psychology of the Chinese people, Bond and Hwang ( 1986 ) asserted that the ability to adapt to different social contexts is characteristic of Chinese people's social behaviors. The Chinese people's social adaptability is influenced by the Confucian thinking that man is a "relational being". The relational perspective dictates the social behaviors of the Chinese people. A given individual could be enmeshed in a variety of relationships at a particular moment in the life cycle. So, a man could be subject to his sovereign, father to his son, son to his father, husband to his wife, and young friend to his elder friend. This tapestry of dualities may seem unmanageable, as it may call forth seemingly incompatible patterns of behaviors of superordination and subordination from the same person. This apparent contradiction in behaviors is, however, not so difficult to manage when seen from a relational perspective on 
the nature of social life. The Chinese are trained to behave accordingly in different social context. The relational perspective of social life cultivates adaptability, not consistency, as the focal issue in the personality development of Chinese people (Bond \& Hwang, 1986).

While the Chinese people feel the strong need to be accepted into the new culture, adapting new behaviors and gaining acceptance is not always easy. Because of the maximum cultural distance between Chinese and the U.S. cultures, the differences in values and behaviors will inevitably influence the Chinese students' adaptation process. Triandis ( 1972) stated that the greater the cultural differences between two cultures, the more acculturative stress. Adopting new behaviors in order to be accepted can present tremendous amounts of stress. During the process, one's original cultural identity may be threatened. Adaptation presents a big challenge. There is a strong desire in the Chinese to be accepted into the new culture, and yet they find it a difficult process. Chinese students are caught in the dilemma of having a strong desire to be accepted and finding it difficult to fulfill the need. As Kim (1988) pointed out, acculturative adaptation may require the sojourners to give up some old behaviors and acquire new behaviors. The situation of acting in certain ways to gain acceptance presents high level of stress for the Chinese students.

Twenty-three situations were perceived as "less stressful" by the majority of the Chinese students. "Less stressful" situations are as rated less than 5 on a 9-point Likert-type scale by the subjects. Of 
the 23 situations, 6 situations are non-communication stressors while 17 situations were communication-related stressors. (For details, see Appendix B). For the percentage of the "less stressful" situations, about $70 \%$ of them were non-communication related. This may indicate that Chinese students tend to view certain noncommunication related situations as less stressful.

There were three interesting situations which were perceived "less stressful" by Chinese students Stressor \#15--Cheating on a test; Stressors \#18--Making child care arrangement; and Stressor \#27-Peer pressure to use alcohol or drugs. For these three situations, the majority of the Chinese respondents said the situations never happened to them, or the situations were not associated with stress for them.

Stressor \#15--cheating on a test as perceived as "less stressful" by Chinese students. This may induce two assumptions that either Chinese students are honest and they do not cheat on a test, or they cheated and did not feel stressful about doing it. After a close look at the survey results, it is noted that $60 \%$ of the students reported that the situation had never happened to them. This supports the first assumption that Chinese students generally do not cheat on tests. A Chinese definition of "cheating on a test" includes two behaviors: looking at notes or books when it is not an open-book test, or asking other students for the answer of a specific question. Stressor \#18--Making child care arrangement was perceived by Chinese students as "less stressful". Sixty-six percent of the students reported that the situation never happened to them. This indicates 
that majority of the students are either single or married with no children.

Stressor \#27---Peer pressure to use alcohol or drug was perceived by Chinese students as "less stressful". The finding may suggest that Chinese students either do not use drug and alcohol or they have not felt stress associated with the behavior. Because $64 \%$ of the students reported that they situation has never happened to them, it is suggested that Chinese students do not have problems with chemical dependency (drugs and alcohol).

The academic-task stressors were positively correlated with the in-class stressors, the social-interaction stressors, and the environment/procedure stressors. Since these three types of situations may be characterized as "short-term, highly communicative, and less personal," the finding suggests that possibly, the students who have higher pressure in academic pursuits may see interaction events as more stressful. It has been noted that Chinese students have an intense commitment to academic success. They might want to devote more time to studies instead of doing socialinteractions and in-class interactions.

The intrapersonal stressors were positively correlated with the other four types of stressors: the academic stressors, the in-class stressors, the environment/procedure stressors, and the socialinteraction stressors. The intrapersonal stressors included situations like 1) Being an international student on campus; 2) anxiety about adopting new behaviors; 3) pressure to create a positive impression to set a high example of my country; 4) 
loneliness for other speakers of my native language; S) pressure of living in two worlds; and 6) deciding between the benefits and disadvantages of leaving my home/family/culture for a university degree. The positive correlations among the intrapersonal stressors and the other four types of stressors suggest that those students who perceive the above mentioned six situations as "more stressful" will also perceive other types of stressors as "more stressful". If the students did not experience high levels of stress in the intrapersonal stressors, their stress level in the other four types of stressors will be low. Again, the researcher does not want to imply that there is a causal relationship between the intrapersonal stressors and other stressors.

The environment/procedure stressors were positively correlated with the in-class stressors, and the social-interactions stressors. The social-interaction stressors were positively correlated with the in-class interaction stressors. The multiple intercorrelations among stressors suggest that these stressors share some common characteristics .

\section{COPING STRATEGIES}

There were 67 coping strategies in the questionnaire. Eleven strategies were identified by Chinese respondents as "used quite a bit" or "used a great deal". If more than $55 \%$ of the subjects rated their use of the coping strategies on the scale of $2=$ used quite a bit or $3=$ used a great deal, the coping strategy will be categorized as a 
"often-used" strategy. The eleven "often-used" strategies by Chinese students were: Coping \#2--I tried to analyze the problem in order to understand it better; Coping \#8--Talked to someone to find out more about the situations; Coping \#1O--Tried to keep my options open, leave things open somewhat; Coping \#14--I tried to keep my feelings to myself; Coping \#27--I accepted the next best thing to what I wanted; Coping \#30--I came out of the experience better than when I went in; Coping \#3 1--Talked to someone who could do something concrete about the problem; Coping \#38--Rediscovered what is important in life; coping \#61--I prepared myself for the worst; Coping \#62--I went over in my mind what I would say or do; Coping \#64--I tried to see things from the other person's point of view (See TAble II).

Among the eleven "often-used" coping strategies, three were the problem-focused coping strategies, three were the focusing-onthpositive coping strategies, two were the keep-to-self coping strategies, two were the seeking-emotional/social support coping strategies, and one was the wishful-thinking coping strategies. Chinese students seemed to prefer these 5 categories of coping strategies while the detachment coping, the self-blame coping, and the tension-reduction/relaxation coping were not used so frequently by Chinese students.

Sue and Kirk (1975) found that Chinese tended to be more practical in their approach to tasks. From the present survey, it is noticed that in times of difficulty and stress, Chinese students usually: (a) tried to analyze the problem in order to understand it 
better; (b) went over in my mind what I would do or say; (c) tried to see things from the other person's point of view. These problemfocused coping strategies involved largely some self-reliant and reflective behaviors. These behaviors involve little interpersonal communication and limited verbal discussion about the problems. Chinese students' coping behaviors may be characterized as more self-reliant, reflective, empathic, with little interpersonal communication and limited verbal expression about the problems. As to the focusing-on-the-positive coping strategy, this approach coincides with the Chinese philosophy of Yin and Yan. "Yin" is the female/negative force, "Yan" is the male/positive force. The Chinese believe that everything in the universe is made up of opposite elements. Life is like a journey over the mountain that has ups and downs. Things have both the negative side and positive side. Even bad events contains positive consequence in them.

The legends and folk stories of a culture often reveal the cultural preoccupations which inform the day-to-day behaviors of the people in that particular culture. The dualistic view that the world consists element of opposite nature Yin and Yan is reflected in a famous proverbial story "Cai Vong Shi Ma". The story talks about a herdsman who lost his horse. In the old times, Cai Vong lived in a village in the Northwest of China. One day he lost his only horse. His neighbors, coming to console him, found him calm and happy. They wondered why he was not upset at all about losing the only horse. Chai Vong said to them: "How would you be so sure that losing the horse is bad?" A few days later, the horse came back, following the 
horse was another herd of horses. This time, the neighbors came to Chai Vong to congratulate him of the good luck. They found him weeping bitterly. Perplexed, the neighbors again asked him why. Chai Vong said: "How would I know this good luck is not going to bring me bad luck?" A few days later, Chai Vong's only son broke his legs when riding the horse. All the villagers felt sorry for Chai Vong and his son. But Chai Vong, despite the tragedy, remained calm and happy. A few years later, a war broke out. All the young men in the village were recruited and got killed in the battles, except Chai Vong's son. Moral of the story: "Fu Yu Yu Huo, Huo Yu Yu Fu"--good luck is disguised in bad events and bad oath may come from a seemingly fortunate event.

The Chinese world view tends to see the world as full of opposite elements which are in harmonious relationship with each other. Positive and negative forces exist in every aspects of life. The Chinese were taught to look at life as having the dual characteristics: bad things can turn out good consequences. "Le Gi Xen Bei" is another common proverb that says too much rejoicing can lead to tragedy. With the philosophical upbringing that believes in "Zhon Yong Zhi Tao--the Middle Path", and with the cultural value in restraining one's inner weakness, the Chinese people are socialized to look at the positive side when something negative occurs. This approach of perceiving the world as consisted of opposite elements have sustained the Chinese people through five thousand years of history with many wars and natural disasters. In times of crisis and difficulty, Chinese students: (a) tried to keep my opinions open, 
leaving things somewhat open; (b) accepted the next best thing to what I wanted; (c) rediscovered what is important in life. These coping strategies by Chinese students are indicative of their ability to look at things from a Yin and Yan approach. Chinese students were able to see things from both the negative and the positive sides, and they were able to learn lessons from past experiences. Among the eleven "often-used" coping strategies reported by Chinese students, three were identified, with a percentage higher than sixty percent, as the "most-often-used" coping strategies (See Table II). The three "most-often-used" coping strategies were: coping \#2 (84\%)-I tried to analyze the problem in order to understand it better; coping \# 27 (61\%)--I accepted the next best thing to what I wanted; 3) Coping \#31 (61\%)--I talked to someone who could do something concrete about the problem. These three most "often-used" coping strategies characterized the coping patterns of Chinese students overseas as practical, realistic, and using a personal support network to solve problems. An important question arises: who comprised the personal support network for the Chinese students? Since the questionnaire did not specify what nationality the good friends refer to, it is necessary to find out the people who are involved in Chinese students' personal support network. By identifying the people who are involved in Chinese students' support network, we can further understand the way Chinese students use their emotional/social support network to cope with stress while they study overseas.

The problem-focused coping was positively correlated with the seek-support coping, the focusing-on-the-positive coping, and the 
self-blame coping. The positive correlations among these four types of coping strategies simply suggests that as the subjects' use of problem-focused coping increases, their use in the focusing-onthepositive coping, and the self-blame coping also increases.

Students who use the problem-focused coping strategies are also inclined to use the seek-support coping, the focusing-on-the-positive coping, and the self-blame coping.

The keep-to-self coping was positively correlated with the detachment coping and the seek-support coping. The self-blame coping was positively correlated with the seek-support coping and the focusing-on-the-positive coping. The multiple positive intercorrelations among the coping strategies suggest that there are common characteristics among these coping strategies. The reported coping strategies were not correlated with the reported stressors. And coping strategies were not correlated with the biodemographic variables of the subjects. 
CHAPTER VI

\section{CONCLUSION}

There are three parts to this chapter. First, conclusions of the data about Chinese university students' biodemographic information, stressors and coping strategies will be briefly summarized. Second, limitations of the present research will be discussed. More specifically, discussion will address limitations regarding the instrument, stressors, and coping strategies suggested in the questionnaire. Third, suggestions for future studies will be provided in regard to the areas that need further explorations. Implications concerning the design of intercultural communication training programs that include the pre-departure training and the afterarrival orientation trainings are presented in hopes to help Chinese sojourners prepare for the sojourning experience and adjust to the new cultural environment.

\section{SUMMARY OF RESEARCH RESULTS}

From the research findings, it has been revealed that Chinese students attending educational institutions face tremendous amounts of stress. The stress includes the traditional student pressure and challenge presented by living in a different cultural setting. For 
Chinese students, the traditional student pressures are the academic task related stressors which specifically include: "getting an A or B on a course" and "studying for a test". The fear of "losing face" as a result of the failure to achieve academic goals is present among Chinese students even though they are seeking education away from home. The concepts of "saving face" and "bringing family a good name" seem to be the main motivation factors that keep Chinese students striving for academic success. The acculturative stress facing Chinese students include the changes brought by studying in a different education system, and living in a different cultural environment. Stress arises from having to deal with certain matters in an unfamiliar system. Because of their intense commitment to achieve academic success, Chinese students tend to sacrifice their personal life pleasure for their academic pursuit. Another stress is related to the conflict of concentrating on academic pursuit and pursuing personal life interests such as dating, marriage, and family plannlng.

Chinese students reported high GPA's and high perceived academic self-efficacy. It is suggested that Chinese students use the high academic self-efficacy as means of coping with stress during their study overseas. Chinese students employed coping strategies that have the problem-focused approach. In coping with stress, Chinese students tend to focus on the positive side of the events. They were able to see the positive side of a seemingly "stressful" situation, and learn from the experience. 
In summary, even though Chinese students face tremendous amounts of stress while attending educational institutions in the United States, they are committed to their academic goals, and in general are successful in their academic pursuit. Chinese students used certain culture specific coping strategies to deal with stress. Their patterns of coping behaviors are characterized as more practical, self-effacing, less person-to-person involvement, and less verbal expressions of their problems.

\section{LIMITATIONS}

Several limitations about the present study need to be addressed. First, two limitations were noticed about the questionnaire: the length of the questionnaire, and the language style used in the questionnaire. The $1 \mathrm{O}$-page questionnaire seemed to be too long. During the data collecting process, the researcher heard many students complain about the length of the questionnaire. The most often heard comments were, "ah, five more pages to go" or "I cannot possibly finish the questionnaire in time to go to class". It usually took the respondents approximately 20 to 30 minutes to complete the questionnaire. Because of the time constraint, the researcher had to go back a second time, or even third time, to gather the completed questionnaire. Also, the scales used in the stressors (form $\mathrm{O}$ to 10 ) were too long. Some Chinese students asked the researcher what was exactly the difference of the stress level between 6 and 7 , or between 8 and 9 on the scale. The researcher 
felt that it would be adequate to use the scale of $\mathrm{O}$ to 5 .

Some of the questions were worded ambiguously i.e. Question \#8--"How many trips to the U.S. of one month or more have you taken?" The respondent could have interpreted the question as ( 1 ) How many times have you been in the United States or (2) How many times have you been in the United States before the present sojourn. For coping strategy \#IO--"I tried to keep my opinions open, leave things open somewhat", and coping strategy \#35 --"I tried not to act too hastily or follow my first hunch," many respondents could not understand some American slang. Due to the lack of knowledge about intercultural communication, many Chinese respondents did not understand the meaning of intercultural communication training. It is suggested that when using a questionnaire with international students, special caution should be adopted to assure that the language style is simple, specific, and technical jargons need to be modified in a language that is understood by the general respondents.

In identifying biodemographic variables, two important variables need further examination. Chinese students reported that they used a personal network for emotional support and to solve problems. However, who constitutes their personal support network was not identified. It is important that the questionnaire ask the students to specify the nationality of the people who were in their support network. Another variable of language proficiency level of the Chinese students need to be included in the biodemographic section of the questionnaire by asking the subjects to rate the 
competence level of their English skill on a scale of $O$ to 5 . Those who have lower competence in language proficiency may report more stress in certain situations where language skill is performed. For example, students who does not feel so competent about their English may be more hesitant to ask questions in class, may participate less social interactions with the U. S. Americans, may report more trouble/stress in dealing with environment/procedure situations. As Graham (1983) noted, a language barrier has been cited as one of the most critical factors in international students' acculturative process. Language proficiency is an important variable, but it was not included in the present research. Knowing the English language proficiency level of the Chinese students will enable the researcher to identify if there are correlations between language proficiency and other variables.

When the situations never happened to the students, they would leave a blank on the scale. From the results of the survey, the majority of Chinese students reported that several of the stressors never happened to them. The situations that the majority of Chinese students did not experience include: Stressor \#13--competing on an athletic team; Stressor \#15--cheating on a test; Stressor \#18--making child care arrangement; Stressor \#27--peer pressure to use alcohol or drugs; Stressor \#39--doing social activities with individuals from the opposite sex or another culture; and Stressor \#40--being asked out on a date. It seems that some of the stressors were not specifically catered to the unique situations of Chinese students but rather, to a larger population of multinational international students. Yet the 
researcher's argument to this issue is that it is necessary to include a broad range of situations that may be associated with stress for the respondents. Through the process of elimination, we will be able to identify what situations are more applicable to Chinese students and what situations do not apply to Chinese students.

For stressor \#40, it is interesting to notice that while $47 \%$ of the students reported that the situation of being asked out on a date had never happened to them, thus no stress associated with the situation, another $53 \%$ of the students reported that they had been asked out on a date, and the situation presented high stress for them. The research finding on the dating issue suggests two assumptions. First, the majority of Chinese students do not date. Second, when Chinese students date, they perceive high stress in the situation of dating. It was discussed in Chapter Five that the Chinese people think marriage and family planning as an important part of life process. It is also noted that Chinese students tend to delay marriage and sacrifice personal life pleasure for their academic commitment. Thus, speculation can be made that Chinese students may deliberately avoid dating. Even if they date, they perceive high stress from the situation. However, the information gathered from the questionnaire was not specific enough to support the above speculations. Since dating is of importance to Chinese students, and the issue represents a source of high stress to them, it would be interesting to further explore whether Chinese students deliberately avoid dating, and when they date, why they perceive high stress from the situation. 
Even though it is noticed that some of the situations in the questionnaire did not apply to Chinese students, it should be noted that the original questionnaire by Dinges and Lieberman (1989) was created for a body of multinational international students. It is inevitable that the questions asked in the original questionnaire would include a broad spectrum of possible situations, and a broad range of coping behaviors that would enable international students from different countries and ethnic groups to find some common ground to answer the questionnaire. However, when used with aparticular cultural group of students, the questionnaire needs to be modified to ensure that the situations included will represent those that are likely to be encountered by that particular culture group.

\section{IMPLICATIONS FOR FUTURE STUDY}

Should this research be replicated, two suggestions are brought toattention. First, it is necessary to identify the people who constitute the personal support network for students. Second, the language proficiency level of the students need to be identified so that researcher will be able to investigate if there is correlation between language proficiency level and other biodemographic variables. It is speculated that language ability may influence the students' academic performance (GPA). Since language is the primary tool of communication, an individual's language ability may also determine how many American friends the person has, or if the person with better language ability will have less communication 
stressors. Language ability may also increase with the length of sojourn. The researcher thinks that the language proficiency of the students is a significant variable. It is necessary to include the language proficiency variable in the research to generate some important data.

Research results indicated that there was a negative correlation between environment/procedure stressors and the Chinese students' GPA's. Though the researcher does not imply that there is a causal relationship between environment/procedure stressors and the students' GPA's, it is possible that when these environment/ procedure stressors are not adequately dealt with, the stressors will influence the students' concentration on the studies, and the students' GPA's may suffer. Certain measurements need be adopted to help Chinese students deal with the environment/ procedure stressors. One good source for help may come from workshops of intercultural communication training programs where information regarding policies and rules about the cultural environment and university procedures are provided.

Based upon the present research it appears that designing intercultural communication programs to prepare soj ourners to manage the challenge of living overseas is not only necessary, but also important. It is suggested that the intercultural communication training programs include two parts: the pre-departure training and the after-arrival orientation programs. The pre-departure training programs will take place in the home culture before sojourner depart for their journey overseas. Though intercultural communication 
programs are virtually non-existent in China (People's Republic of China), with the tremendous amount of international business transactions between China and other countries, and the many exchange programs between Chinese government and foreign institutions and organizations, the importance of intercultural communication to promote better understandings about people of different cultural origins need to be emphasized. Eventually, if China wants to conduct more international business transactions, and benefit from academic exchange programs with non-Chinese institutions, the importance of intercultural communication training should be recognized and implemented in order to help the Chinese to further understand cultures other than their own.

General pre-departure programs should include crucial information about the nature of culture shock process every sojourners experience, language training, and information about the use of nonverbal signs and symbols in the perspective sojourning culture. The research result indicated that $77 \%$ of Chinese students had no intercultural communication training, and many of them did not know the concept of 'culture shock.' From my personal observations during contacts with Chinese students in Portland area, many of them went through 'culture shock' with various degree of intensity in psychological disorientation and psychosomatic illness. Though scholars agree that there is no quick cure for culture shock symptoms, knowing about the nature of culture shock will help sojourners understand what they are going through, and they can then deal with culture shock in ways they feel comfortable. Since 
Chinese students have the tendency to use the problemfocused approach to solve problems, providing knowledge about culture shock will give Chinese students the data base to analyze and solve their own problems. When designing pre-departure training programs for a particular group of people with specific sojourning purposes, more specific information needs to be considered to meet the needs of the perspective sojourners. It is suggested that general pre-departure training should include information about culture shock, language training programs, and knowledge about the use of nonverbal signs and symbols of the host culture.

In urban educational institutions where there is a considerable amount of international student enrollment, there should be some after-arrival orientation programs available to help the international students on campus to adjust to the new environment. Orientation programs need to provide information about university policies and rules regarding registration, use of educational facilities (library, computer center, language laboratory, etc.) Other information may include knowledge about the public transportation system, and health care service. Because Chinese students tend to concentrate on studies and minimize personal life and social activities, programs need to be organized to involve Chinese students in social activities. However, when planning these social activities, caution should be taken to prevent the "enclave" phenomenon. from occurring. Kohls ( 1984 , p. 63 -65) observed that when people live overseas for an extended period of time, they experience psychological disorientation such as hyper-irritability, resentment to the host culture, 
withdrawal, and depression. In the stage of withdrawal, sojourners tend to seek out their own countrymen and stay together with them, avoiding meaningful interactions with people from the host culture. The "enclave" phenomenon is not helpful to intercultural learning and growing. On the contrary, it may increase the sojourners' feeling of isolation and exclusion. Thus, social activities should involve not only Chinese students, but also some American participants. These social activities, when facilitated properly, can increase intercultural understandings between Chinese students and people from the host culture. In his 1983 study, Graham noted that Chinese felt most "unloved" and "excluded" on campus. A well-planned social activitycan serve the purpose of decreasing the common-felt feelings of isolation and exclusion by Chinese students.

The present study was inspired by Dinges and Lieberman's 1989 study of international students' communication stressors and their coping strategies. After Dinges and Lieberman's 1989 study, two replica studies focusing on the Japanese and the Chinese students have been conducted separately by two graduate students at Portland State University, Department of Speech Communication to examine the stressors and coping strategies that were experienced by Japanese and Chinese students (the two replica studies include the thesis by Atsuko Kurogi and the present study). Even though the Chinese and the Japanese cultures share many similarities in values and beliefs, there are still some basic cultural differences between the two cultures. The Chinese and the Japanese students' perceptions of stressors and their ways of dealing with stress may be different. 
It will be of academic interest to combine the results of these two separate studies to examine, in a cross-cultural context, what the differences are in the perceived stressors and the coping behaviors between Chinese and Japanese students.

The present study has provided information about the stressors and particular coping strategies employed by Chinese students attending educational institutions in the greater Portland area. Results of the present study fill a void in the study of intercultural communication and the information gathered is a significant step toward understanding the acculturation difficulties Chinese students experience. The information about specific stressors and coping strategies employed by Chinese students can be used by those who interact with Chinese students professionally or personally, i.e. professors and faculty members, campus counselorsand academic advisors. Also, the information derived from the present study can be used to design intercultural communication training programs such as pre-departure preparation and afterarrival orientation training. Future studies and programs designed to examine cross-cultural differences in stressors and coping strategies of different cultural groups may benefit from the results of the present study. 


\section{REFERENCES}

Abbot, K. A. (1970). Harmony and individualism. Taipei: Orient Cultural Services.

Adler, P. S. ( 1972). Culture shock and the cross cultural learning experience. In Hoopes, D. S. (Ed.) Readings in Intercultural Communication. Vol.II. Pittsburgh: Regional Council for International Education.

Adler, P. S. (1975). The transitional experience: an alternative view of culture shock. Journal of Humanistic Psychology, 15(4), pp. 1 3-23.

Bandura, A. (1977). Self-efficacy: toward a unifying theory of behavioral change. Psychological Review, 84(2), 191-215.

Barna, L. M. (1976). How culture shock affects communication. Communication. 5(1), 1-18.

Barna, L. M. (1983). The stress factor in intercultural relations. In Brislin, R. W., Landis, D \& Brandt, J. (Eds.), Handbook of intercultural training. Vol. II, pp. 19-49. New York: Pergamon Press.

Barna, L. M. (1988). Stumbling blocks in intercultural communication. In Porter,L. A. \& Samovar,R. E (Eds.), Intercultural communication: a reader (5th ed.), pp. 322-330. Belmont, CA: Wadsworth .

Berger, K. and Luckmann,G. (1967). The social construction of reality. Anchor Books.

Berry, J. W. (1979). Psychology of social change. In Triandis, H. \& Brislin, R (Eds.), Handbook of cross-cultural psychology. Vol.5. Boston: Allyn \& Bacon. 
Bond, M. H. and Hwang, K. K. (1986). The social psychology of Chinese people. In Bond, M.H. (Ed.) The psychology of the Chinese people. Oxford University Press.

Bois, C. D. (1956). Foreign students and higher education in the United States. Washington D. C. American Council on Education Brislin, R. W. (1981). Cross cultural encounters: face-to-face interaction. New York: Pergamon Press.

Cassel, J. (1970). Physical illness as a response to stress. In Levine, S. \& Scotch, N.A. (Eds.), Social Stress. Chicago: Aldine.

Ching, W. and Prosen, S. S. (1980). Asian-American counseling: a case of cultural dissonance. Journal for specialist in group work. 5(4), 228-232.

Cieslak, E. C. (1955). The foreign graduate student in American colleges. Detroit: Wayne University Press.

Condon, J. C. and Yousef, F. (1975). An introduction to intercultural communication. Indianapolis, Indiana: The Bobbs-Merrill.

Dinges, N. and Lieberman, D. ( 1989). Stressors and coping strategies among international students: implications for classroom practice. Paper presented at the World Communication Association Convention, Singapore.

Fisher, S. (1986). Stress and strategy. Hillsdale, New Jersey: Lawrence Erlbaum Associates.

Furnham, A. (1987). The adjustment of sojourners. In Kim, Y.Y. \& Gudykunst, W. B. (Eds.) Cross-cultural adaptation--current approaches. pp. 42-61. Newbury Park, CA: Sage Publications.

Furnham, A. and Bochner, S. (1982). Social difficulty in a foreign culture: an empirical analysis of culture shock. In S. Bochner (Ed.) Cultures in contact. pp. 161-198. N.Y: Pergamon Press.

Furnham, A. and Bochner, S. (1986). Culture shock-psychological reactions to unfamiliar environments. New York: Methuen. 
Graham, M. A. (1983). Acculturative stress among Polynesian, Asian, and American students on the Brigham Young UniversityHawaiian campus. International Journal of Intercultural Relations. 7(1). 79-103.

Gudykunst, W.B. and Kim, Y. Y. (1984). Communication with strangers. New York: Random House.

Gudykunst, W.B . and Nishida, T. ( 1986). Attributional confidence in low- and high-context cultures. Human Communication Research. 12(4), pp. 525-549.

Hall, E. T. (1976). Beyond culture. Garden City, N. Y. Doubleday \& Company.

Hall, E. T. (1988). Context and meaning. In Porter, R. E. \& Samovar, L. A(Eds.) Intercultural Communication: A Reader. Belmont, CA: Wadsworth Publishing Company.

Harris, P. R. and Moran, R. T. ( 1977). Managing cultural differences . Houston: Gulf Publishing.

Harris, P. R. and Moran, R. T. (1982). Understanding cultural differences. In Intercultural communication: a reader. R. E. Porter and L. A. Samovar (Eds.) 3rd ed., pp.62-72. Belmont, CA: Wadsworth.

Hofstedt, G. (1984). Culture's consequences: international differences in work related values. Beverly Hills, CA: Sage Publications.

Hofstedt, G. (1986). Cultural differences in teaching and learning. Intercultural Journal of Intercultural Relations. 3 , pp. 301 331 .

Howard, N. H. ( 1979). Cultural issues in providing psychological services for foreign students in the United States. International Journal of Intercultural Relations. Vol.III. pp.49-85.

Hsu, F. L. K. (1971 a). A hypothesis on kinship and culture. In Hsu, F.L.K. (Ed.), Kinship and culture. pp.3-30. Chicago: Aldine. 
Hsu, F. L. K. (1971 b). Filial piety in Japan and China: borrowing, variations and significance. Journal of Comparative Family Studies, $\underline{2}, 67-74$.

Hu, H. C. (1944). The Chinese concept of face. American Anthropologist, 46, pp. 45-64.

Institute of International Education (1987). Statistical abstract of the United States. (109th ed.), U. S. Bureau of the Census.

Kim, Y. Y. (1988). Cross-cultural communication and adaptation. Newberry Park, CA: Sage Publications.

Kim, Y. Y. (1989). Intercultural adaptation. In M. K. Asante \& W. B. Gudykunst (Eds.), Newberry Park, CA: Sage Publications.

Kim, Y. Y. and Gudykunst, W. B. (1987). Cross-cultural adaptation: current approache. Sage Publications.

King, A. Y. C. and Bond, M. H. (1985). The Confucian paradigm of man: a sociological view. In W. S. Tseng \& D. Y. H. Wu (Eds.), Chinese Culture and Mental Health. pp. 29-46. New York: Academic Press.

Kitano, H. L. (1976). Japanese-Americans: the evolution of a subculture. Englewood Cliffs, NJ: Prentice-Hall.

Kurogi, A. (1990). Communication stressors and coping strategies among Japanese students. Unpublished master's thesis. Portland State University.

Kohls, L. R. (1984). Survival kits for oversea living. Yarmouth, Maine: Intercultural Press Inc.

Landis, D. and Brislin, R. (1983). Handbook of Intercultural Training. New York: Pergamon Press.

Lazarus, R. S. (1969). Patterns of adjustment and human effectiveness. New York: McGraw-Hill Book Company.

Lazarus, R. S. (1971). The concept of stress disease. In Levi, L. (Ed.) Society stress and disease. Vol. I. pp. 53-60. 
Lazarus, R. S. (1979). Positive denial: the case for not facing reality. Psychology Today, pp. 44-60.

Lazarus, R. S. (1985). Stress and coping: an anthology. (2nd ed.)

New York: Columbia University Press.

Lazarus, R. S. and Folkman, S. (1984). Stress, appraisal, and coping. New York: Springer Publishing Company.

Littlejohn, S. W. (1983). Theories of human communication. (2nd ed.) Belmont, CA: Wadsworth.

Maslow, A. H. (1968). Motivation and Personality. New York: Harper \& Row.

Mechanic, D. (1970). Some problems in developing a social psychology of adaptation to stress. In McGrath, J E. (Ed.), Social and psychological factors in stress. Chicago: Holt, Rinehart \& Winston.

Meichenbaum, D. (1975). A self-instructional approach to stress management: a proposal for stress inoculation training. In Spielberger, C. D. \& Sarason, I. G. (Eds.), Stress and anxiety, Vol. I. pp.317-330. Washington, D. C.: Hemisphere Publishing.

Murray, D. P. (1988). Face-to-face: American and Chinese interactions. In Porter, R. E. \& Samovar, L.A. (Eds.), Intercultural Communication: $\underline{A}$ Reader. pp. 94-100. Belmont, CA: Wadsworth.

Oberg, K. (1954). Culture shock. Indianapolis: Bobbs-Merrill Company.

Oberg, K. (1960). Culture shock: adjustment to new cultural environments. Practical Anthropology, 7, 170-179.

Oberg, K. (1972). Culture shock and the problem of adjustment to new cultural environments. In Hoopes, D.S. (Ed.), Readings in intercultural communication, Vol. II. Pittsburgh: Regional Council for International Education. 
Porter, R. E. ( 1972). An overview of intercultural communication. In Porter, R.E. \& Samovar, L.A. (Eds.), Intercultural communication: a reader. Belmont, CA: Wadsworth.

Porter, R. E. and L. A. Samovar (1982). Intercultural communication: a reader. (3re ed.) Belmont, CA: Wadsworth.

Porter, R. E. and L. A. Samovar (1988). Intercultural communication: a reader. (5th ed.) Belmont, CA: Wadsworth.

Portland State University International Student Services, Student Statistics, Fall, 1989.

Pusch, M. D. (1981). Multicultural Education: A Cross-Cultural Training Approach. Chicago: Intercultural Press.

Rabkin, J. G. and Struening, E. L. (1976). Life events, stress, and illness. Science, 194, pp.1013-1020.

Ruben, B. D. (1983). a system-theoretic view. In W. B. Gudykunst (Ed.), Intercultural communication theory. New Bury, CA: Sage.

Scaff, M. K. and Ting, M. G. (1972). Fu Tao: guidance in Taiwan seeks a value orientation. Personnel and Guidance Journal, 50(8), pp. 645-654.

Schutz, W. (1966). The interpersonal underworld. Palo Alto, CA: Science \& Behavior Books.

Sellitz, C., Christ, J. R., Havel, J., \& Cook, S. W. (1963). Attitudes and social relations of foreign students in the United States. Minneapolis: University of Minnesota.

Sharma, S. (1973). A study to identify and analyze adjustment problems experienced by foreign non-European graduate students enrolled in selected universities in the State of North Carolina. California Journal of Educational Research. 24(3), pp. $135-146$.

Spradley, J. P. and Phillips, M. (1972). Culture and stress: a quantitative analysis. American Anthropologist, 74(3), pp. 518-529. 
Sue, D. W. (1972). Counseling Chinese-Americans. Personnel and Guidance Journal, $\underline{50}$ (8), pp. 637-644.

Sue, D. W. (1973). Understanding Asian-Americans: the neglected minority. Personnel and Guidance Journal, 51, pp. 386-389.

Sue, D. W. (1977). Barriers to effective cross-cultural counseling. Journal of Counseling Psychology, 24, pp. 420-429.

Sue, D. W, and Kirk, B. A. (1975). Asian Americans: use of counseling services on a college campus. Journal of Counseling Psychology. $\underline{22}$, pp. 84-86.

Triandis, H. C. (1972). The analysis of subjective culture. Wiley, New York.

Triandis, H. C. and Brislin, R. E. (1988). Cross-cultural training across the individualism-collectivism divide. International Journal of Intercultural Relations, 12(3), pp. 269-289. 
APPENDIX A

BIODEMOGRAPHICS 
Except where noted, please write the number of your answer to the right of each item.

1. How old are you?

2. what is your sex?

$1=$ male $2=$ female

3. what country are you from?

4. What is your current academic standing?

l=freshman $2=$ sophomore $3=$ Junior $4=$ senior $5=$ Graduate $\quad 6=\mathrm{ESL}$

5. What do you think your current G. P. A. is ?

6. How long have you been in the U.S.?

7. Did you have any intercultural training for this trip/sojourn before you left your home country?

8. How many trips to the U.S. of one month or more have you taken?

9. How long do you plan to live in the U.S.?

$1=$ less than 6 months $2=6$ months to 1 year $3=$ from $1-3$ years $\quad 4=$ from $3-5$ years $\quad 5=$ indefinitely

10. How many good American friends do you have?

USING THE SCALE BELOW, WRITE THE NUMBER WHICH INDICATE:

$\begin{array}{lllllllllll}0 & 1 & 2 & 3 & 4 & 5 & 6 & 7 & 8 & 9 & 10\end{array}$

Not at all confident Moderately confident highly confident

1. How confident are you in completing the academic term?

2. How confident are you in completing the academic year?

3. How confident are you in completing your degree? 


\section{APPENDIX B}

STRESSORS CATEGORIZATION 


\section{CATEGORY I}

\section{COMMUNICATION STESSORS}

\section{(1) In-class Interaction Stressors}

2) Being Singled out in class as a spokesperson for international students.

3) Asking a question in class.

5) Acting as if I am from the United States, to gain acceptance from classmates (non-international).

6) Giving a class presentation 19) Conflict with instructor(s).

20) Personal contact with the faculty.

22) Speaking English.

24) Lack of assertiveness or ability to speak up for own beliefs

26) Being called on in class.

28) Making an appointement to meet a professor in their office.

29) Knowing when it is appropriate to make a comment in class.

33) Asking other students to explain class material

(2) SOCIAL INTERACTION STRESSORS

13) Competing on an athletic team.

14) Peer pressure to take part in time-consuming extra curicular (social) activities.

25 ) Interacting with large groups of people for the first time. 
27) Peer pressure to use alcohol or drugs.

31) Asking someone I do not know to go to a social activity.

34) Discussing cultural problems with other students.

35) Discussing personal life problems with other students.

38) Being around people from many different cultures.

39) Doing social activities with individuals from the opposite

sex and another culture.

40) Being asked out on a date.

41) Asking someone out on a date.

42) Having intimate relation.

43) Socializing over a meal.

44) Responding to obvious negative remarks about my culture.

\section{(3) ENVIRONMENT/PROCEDURE STRESSORS}

18) Making child care arrangemnts for childre.

21) Asking people about university policies, rules and services.

31 ) Register for classes.

33) Using public transportation to go to school.

44) Finding a place to live.

45) Asking for career/professional advice from faculty and school staff.

48) Getting needed health care

49) buying textbooks.

50) Ordering food on campus. 


\section{NON-COMMUNICAITON STRESSORS}

\section{(1) Academic Task Stressors}

9) Receiving a D or F on a test.

11) Pressre to get an A or B in a course.

15) Cheating on a test.

16) Failing to complete assignments.

17) Studying for a test.

37) Taking an examination.

\section{(2) Intrapersonal communication stressors}

1. Being an international student on your campus.

4) Anxiety about adopting behaviors I never had before.

7) Pressure to create a positive impression, set a high example for my country.

8) Loneliness for other speakers of my native language.

10) Pressure of living ; two worlds (my culture and this culture) with different sets of expectations for me.

12) Deciding between the benefits and disadvantages of leaving my home/family/culture for a university degree. 


\section{APPENDIX C}

\section{COPING STRATEGIES CATEGORIZATION}




\section{PROBLEM-FOCUSED COPING STRATEGIES}

1) Just concentrated on what I had to do next - the next step.

2) I tried to analyze the problem in order to understand it better.

7) I tried to get the person responsible to change his or her mind.

26) I made a plan of action and followed it.

35) I tried not to act too hastily or follow my first hunch.

39) Changed something so things would turn out all right.

46) Stood my ground and fought for what I wanted.

48) Drew on my past experiences; I was in a similar situation before.

49) I knew what had to be done, so doubled my efforts to make things work.

52) Came up with a couple of different solutions to the problem.

54) I tried to keep my feelings from interfering with other things too much.

62) I went over in my mind what I would say or do.

64) I tried to see things from the other person's point of view.

65) I reminded myself how much worse things could be.

\section{WISHFUL-THINKING COPING STRATEGIES}

11) Hoped a miracle would happen.

34) Took a big chance or did something very risky.

50) Refused to believe it happened. 
55) Wished that I could change what had happened or how I felt.

57) I daydreamed or imagined a better time or place than the one I was in.

58) Wished that the situation would go away or somehow be over with.

61) I prepared myself for the worst.

\section{DETACHMENT COPING STRATEGIES}

3) Turned to work or substitute activity to take my mind off things. 4) I felt that time would make a difference---the only thing to do was to wait.

12) Went along with fate; sometimes $I$ just have bad luck. 13) Went on as if nothing had happened.

21) Tried to forget the whole thing.

24) I waited to see what would happen before doing anything.

36) Found new faith.

41) Did not let it get to me; refused to think too much about it.

44) Didn't take the situations so seriously; refused to get too serious about it.

53) Accepted it, since nothing could be done.

\section{SEEKING-EMOTIONAL-SOCIAL-SUPPORT COPING STRATEGIES}

8) Talked to someone to find out more about the situation. 18) Accepted sympathy and understanding from someone. 
22) I got professional help.

28) I let my feelings out somehow.

31 ) Talked to someone who could do something concrete about the problem.

42) I asked a relative or friend I respected for advice.

45) Talked to someone about how I was feeling.

50) I prayed.

67) I sought advice from a spiritual guide or tribal leader.

\section{FOCUSING-ON-THE-POSITIVE COPING STRATEGIES}

5) Bargained or compromised to get something positive from the situation.

6) I did something which I didn't think would work, but at least I amdoing something.

10) Tried to keep my options open, leave things open somewhat.

15) Looked for the positive aspects; tried to look on the bright side of things.

20) I was inspired to do something creative.

23) Changed or grew as a person in a good way.

27) I accepted the next best thing to what I wanted.

38) Rediscovered what is important in life.

63) I thought about how a person I admire would handle this situation. 


\section{SELF-BLAME COPING STRATEGIES}

9) Criticized or lectured myself.

25) I apologized or did something to make up.

29) Realized I brought the problem on myself.

51 ) I made a promise to myself that things would be different next time.

56) I changed something about myself.

\section{TENSION-REDUCTION/RELAXATION COPING STRATEGIES}

16) Slept more than usual.

17) I expressed anger to the person(s) who caused the problem.

32) Got away from it for a while; tried to rest or take a vacation.

33) Tried to make myself feel better by eating, drinking, smoking, using drugs or medication, etc.

47) Took it out on other people.

66) I jogged, worked out or exercised.

\section{KEEP-TO-SELF COPING STRATEGIES}

14) I tried to keep my feelings to myself.

19) I told myself things that helped me to feel better.

30) I came out of the experience better than when I went in.

37) Maintained my pride.

40) Avoided being with people in general.

43) Kept others from knowing how bad things were. 